\title{
IMMUNE SYSTEM CHALLENGE IMPROVES COGNITIVE-BEHAVIOURAL RESPONSES AND REVERSES MALARIA-INDUCED COGNITIVE IMPAIRMENT IN MICE
}

Luciana Pereira de Sousa Vieira ${ }^{\#}$, Flávia Lima Ribeiro-Gomes ${ }^{1 \#}$, Roberto Farina de Almeida2+, Tadeu Mello e Souza², Guilherme Loureiro Werneck ${ }^{3}$, Diogo Onofre Gomes de Souza² \& Cláudio Tadeu Daniel-Ribeiro ${ }^{1 *}$

${ }^{1}$ Laboratório de Pesquisa em Malária, Instituto Oswaldo Cruz \& Centro de Pesquisa, Diagnóstico e Treinamento em Malária (CPD-Mal) of Fundação Oswaldo Cruz (Fiocruz) and of Secretaria de Vigilância em Saúde (SVS), Ministério da Saúde; 2Departamento de Bioquímica, Universidade Federal do Rio Grande do Sul; and ${ }^{3}$ Departamento de Epidemiologia of Instituto de Medicina Social, Universidade do Estado do Rio de Janeiro and Instituto de Estudos de Saúde Coletiva da Universidade Federal do Rio de Janeiro, Brazil.

* Corresponding author at Laboratório de Pesquisa em Malária, Instituto Oswaldo Cruz, Fiocruz. Av. Brasil 4365, Manguinhos, Rio de janeiro. CEP 2104-360, RJ Brazil. E-mail malaria@fiocruz.br.

\# These authors contributed equally to the work.

+ Present address: Programa de Pós-Graduação em Ciências Biológicas, Instituto de Ciências Exatas e Biológicas, Universidade Federal de Ouro Preto, Minas Gerais, Brazil.

\begin{abstract}
Elements of the immune system are necessary for healthy neurocognitive function, and the pattern of the immune response triggered by different exogenous stimuli may induce regulatory or deregulatory signals that can affect nervous functions. Here we investigate the effect of immune stimulation on behavioural parameters in healthy mice and its impact on cognitive sequelae resulting from non-severe experimental malaria. We show that the immune modulation induced by a specific combination of immune stimuli, classically described as capable of inducing a major type 2 immune response, can improve the long-term memory of healthy adult mice and prevent the negative cognitive-behavioural impairments caused by a single episode of mild Plasmodium berghei ANKA malaria. This finding has implications for the development of immunogens as cognitive adjuvants.
\end{abstract}

\section{INTRODUCTION}

The immune and nervous systems may be categorized as plastic cognitive systems due to their ability to recognize real world objects, including microbes, and to their ability to adapt through experience. Following antigenic or sensory stimulation, vertebrate organisms undergo changes in the cellular connections of their immune and nervous systems that alter their abilities and structures. There is considerable evidence for the existence of strong interactions between these two systems ${ }^{1-7}$. Immunomodulation of the nervous system can occur through either physiological or 
pathological mechanisms. The maturation and homeostasis of nervous cognitive abilities require the participation of components of the immune machinery ${ }^{6-7}$. Exogenous immune stimuli may also have positive or negative effects on the nervous system, depending on the nature and intensity of the immune response elicited ${ }^{1-4,6}$.

Studies on the effects of immune stimuli on brain function have found evidence for i) maternal immune stimulation impairing the neurocognitive performance of offspring ${ }^{8-9}$, ii) both beneficial and harmful effects of neonate vaccination on neuronal plasticity and cognitive function in adulthood ${ }^{10}$, iii) the damaging impact of systemic inflammatory stimuli on the cognitive function of adult mice ${ }^{11-12}$, and iv) neurocognitive dysfunction in both human and experimental models of some infectious diseases ${ }^{13-27}$.

Cerebral malaria (CM), the most severe complication of malaria caused by Plasmodium falciparum, can result in neurocognitive sequelae, including motor deficits, behavioural alterations and severe learning difficulties ${ }^{15}$. Long-term negative effects are more common in Africa where the prevalence of falciparum malaria and CM is higher ${ }^{28}$. Some of these sequelae are also observed in Plasmodium berghei ANKA $(P b A)$ infected C57BL/6 mice, a well-studied model of experimental CM (ECM) ${ }^{27}$. In recent years, cognitive impairment, mainly related to learning and memory, has also been reported in residents of endemic regions presenting with non-severe malaria ${ }^{29-}$ 31. This phenomenon has also been observed in non-severe malaria infections in mice $^{32}$, in which the ECM model was adapted to assess the neurocognitive alterations that occur following a short-term episode of non-severe malaria. Using this adapted model, here we evaluate the effects of immune stimuli on behavioural paradigms such as memory and anxiety, following a mild malaria episode or during homeostasis.

Given the known effect of the immune system on neurocognitive functions, we hypothesized that immune stimulation may affect cognitive performance. Our results show a beneficial effect of immune stimulation on cognitive-behavioural parameters in healthy mice and a reversal of the cognitive impairment caused by malaria parasite infection.

\section{RESULTS}

\section{Type 2 immune stimuli improve long-term memory in healthy mice}

To study the effect of immune stimuli on behavioural paradigms, immunogens were chosen according to the pattern of immune response induced. Three immune stimulation strategies were used: T1 and T2 strategies employed well-known antigens able to induce type 1 and type 2 immune responses, respectively $33-47$, and a "Pool" strategy was created by the combination of T1 and T2 strategies, described in further detail in the Material and Methods section. Briefly, mice were infected with Plasmodium berghei ANKA, treated from the fourth day after infection on for seven days, and allowed to rest for thirteen days before being immune stimulated with different strategies (Fig. 1).

The effects of immune responses on locomotion and long-term spatial habituation were assessed via established protocols ${ }^{32}$ in mice subjected to two different sessions of the open field task (OFT), with training (OF1, $10 \mathrm{~min}$.) and test (OF2, $10 \mathrm{~min}$.) sessions 24 hours apart. At the training session, a high rate of locomotor activity is commonly 
observed. Surprisingly, mice immune stimulated with Pool or T1 strategies showed reduced total OF1 locomotion when compared to non-immune stimulated mice (Extended data, Fig. 1a).

Commonly, after the training session [first OFT (OF1), exposure], exploratory behaviour decreases as the stress related to novelty disappears, and is usually significantly lower after 10 minutes of task performance $32,48-49$. Both non-immune stimulated (Control group) and immune stimulated (Pool, T1 and T2 groups) mice displayed decreased locomotion in the test session (OF2) compared to the training session (OF1) (Extended data, Fig. 1a), as expected. These results indicate that immune stimulation did not affect long-term habituation memory.

Twenty-four hours later mice were subjected to the novel object recognition test (NORT) in the same open field arena. During the training session, a similar exploratory activity of familiar objects (FO1 and FO2) is expected and was observed in all groups of mice (Control, Pool, T1 and T2) (Fig. 2a; Extended data, Fig. 2a), with a mean exploration of 25 seconds (data not shown). Remarkably, mice immune stimulated with the Pool or T2 strategies presented significantly higher recognition memory performance in relation to the Control group during the test session, performed 24 hours later. Mice submitted to the T1 strategy did not differ from the Control group (Fig. 2c; Extended data Fig. 2c). These data indicate that immune stimulation with immunogens that induce type 2 immune responses may enhance long-term recognition memory in healthy mice.

\section{Immune stimulation of healthy mice did not generate an anxiety-like state}

In addition to exploratory activity, the OFT also allows the evaluation of phenotypes related to anxiety-like behaviour through analysis of the dwell time or the locomotion rate in the centre of the open field arena during the first exposure to the apparatus. Immune stimulated mice (Pool, T1 and T2 groups) showed no difference in dwell time (data not show) but presented significantly reduced locomotion in the centre of the open field arena in relation to the non-immune stimulated mice (Control group) (Fig. 3a). It seems, however, that this observation may have been influenced by the total reduced locomotion observed in animals submitted to Pool and T1 strategies (Extended data, Fig. 1a). Since no conclusion about anxiety-related behaviour can be confidently extrapolated from these data, we used the light-dark specific task, a conflict avoidance test, to address this issue. In this test, immune stimulated mice (Pool, T1 and T2 groups) clearly behaved similarly to mice of the Control group, remaining an equal time in the light zone (Fig. 3c), and thus implying that immune stimulation did not generate an anxiety-like state.

\section{Exposure to type 2 immune stimuli may reverse cognitive-behavioural damage caused by non-severe $\boldsymbol{P}$. berghei ANKA infection}

About $92 \%$ of the world's malaria cases are due to Plasmodium falciparum, 1 to $2 \%$ of which progress to cerebral malaria. Therefore, about $90 \%$ of all malaria cases globally are caused by this lethal species of Plasmodium and occur without apparent clinical complications $^{28}$. Despite the apparent 'non-severe' nature of these cases, there is growing evidence that non-severe malaria may impair the cognitive development of children ${ }^{29-31}$. 
145 The experimental model we have previously described uses $P b A$-infected C57BL/6

146 mice treated at day 4 post-infection, prior to the appearance of the clinical signs of CM.

147 In our opinion, the main advantage of such a model is that it best mimics the human

148 situation described above that corresponds to the large majority of malaria cases in

149 the world; non-severe falciparum malaria with timely treatment ${ }^{28}$. Using this model, we

150 have been able to observe a long-term cognitive-behavioural impairment related to

151 memory and anxiety as late as 82 days after the end chloroquine (CQ) treatment, when

152 no parasites are present tin the blood $^{32}$.

153 Given the beneficial effect of immune stimulation on long-term memory in healthy mice described above, we evaluated the effect of the same immune stimuli in mice with behavioural alterations caused by non-severe malaria infection. PbA-infected and treated mice (from here on referred to as the "Infected group"), did not display reduced total locomotion in the training session of the OFT when compared to healthy mice (Extended data, Fig. 1b). However, infected and immune stimulated animals (Inf-Pool and Inf-T2 groups) showed a significant reduction in locomotion in the OF1 when compared to healthy mice (Extended data, Fig. 1b). Control, infected and infectedimmune-stimulated groups (Inf-Pool and Inf-T2, but not Inf-T1) displayed normal behaviour with a significant decrease in locomotion in the test session as compared to the training session of the OFT (Extended data, Fig. 1b).

As expected, there was no object preference in the NORT training session since all mice explored both familiar objects for the same length of time (for a mean of 25 seconds; data not show) (Fig. 2b, Extended data, Fig. 2b). Consistently, infected mice presented long-term recognition memory sequelae that manifested as similar exploration of the familiar object (FO) and new object (NO) in the NORT. This 169 impairment disappeared following stimuli with Pool or T2 immunization (Fig. 2d, 170 Extended data, Fig. 2d), pointing to a beneficial effect of immune stimulation triggered 171 by type 2 immunogens in reversing of the cognitive deficits associated with malaria.

$P$. berghei ANKA infection in mice induces an anxiety-like behaviour that is reversed by immune stimulation with type 2 immunogens

174 The distance travelled in the periphery and in the centre of the open field arena are inversely related. Since the latter was decreased in PbA-infected mice (Fig. 3b) and no change in the locomotion during the training session (OF1) occurred among Control and Infected groups (Extended data, Fig. 1b), the decrease may be interpreted as the expression of an anxiety-like behaviour. This behaviour was confirmed by the observation of a reduction in time spent, by infected mice, in the light zone of the lightdark task, a more sensitive and widely used test to evaluate anxiety-related parameters in rodent. The anxiety-like behaviour was reversed by Pool and T2, but not by T1, strategies of immune stimulation (Fig. 3d).

Immune stimulation procedures and non-severe $\boldsymbol{P}$. berghei ANKA malaria elicit immune responses

186 The specific immune responses triggered by the immunogens in the Pool, T1 and T2 strategies (tetanus toxoid, influenza, PfMSP3 and OVA) were evaluated at the end of the behavioural task experiments, and the effectiveness of the stimuli was confirmed (Extended data, Fig. 3a,b,c,d). No specific humoral immune response was observed 190 against diphtheria toxoid (data not show), confirming previous observations of the low 191 immunogenicity of diphtheria toxoid in mice compared to other experimental models ${ }^{50}$. 
192 At the time the immune responses were evaluated (84 days after the end of CQ 193 treatment), non-immune stimulated infected animals did not present increased levels 194 of serum cytokines when compared to the Control group (Extended data, Fig. 195 4a,b,c,d). However, higher levels of TNFa, IFN $\gamma$, IL-6, IL-10 and/or IL-4 were detectable 196 in all groups of mice stimulated with T1, T2, or Pool strategies (Extended data, Fig. $4 a, b, c, d)$, ratifying the immune stimulation by the different strategies used. Interestingly, only IL-10 was consistently increased among healthy and infected mice stimulated with Pool or T2 strategies, although statistical significance was not achieved between Pool and Control groups (Extended data, Fig.4e).

We evaluated the splenic immune response of healthy and infected mice exposed to Pool and T2 strategies, since only these approaches were able to immunomodulate the cognitive behaviour of mice. The immune stimulated healthy mice showed increased spleen weight and total number of splenocytes (Extended data, Fig. 5a,b,c). The weight and total number of splenocytes in Infected animals were not different to those in the Control group (Extended data, Fig. 5a,b,c). As observed in healthy immune stimulated animals, immune stimulation of $P b A$-infected mice via Pool or T2 strategies induced splenomegaly (Extended data, Fig. 5a,b,c).

Healthy mice immune stimulated with either Pool or T2 strategies presented similar patterns of modulation of different immune components. We observed an increase in the frequency of splenic B cells (Extended data, Fig. 6b), CD4 and CD8 T cells with central memory phenotype (Extended data, Fig. $7 \mathrm{~d}, \mathrm{~g}$ ) and CD4 T cells with regulatory function (Treg cells) (Extended data, Fig. 6e) in both Pool and T2 immune stimulated groups when compared to non-immune stimulated animals. A reduction in the frequency of CD8 T cells was also observed in mice immune stimulated with the T2 strategy when compared to the Control group (Extended data, Fig. 6d).

PbA-infected mice had higher frequencies of B cells, total CD4 and CD8 T cells (Extended data, Fig. 6a,b,c), and CD4 and CD8 T cells with naïve and central memory phenotypes (Extended data, Fig. 7a,b,e,d,g) when compared to healthy mice (Control group). The frequency of Treg cells, however, was similar between infected and healthy mice (Extended data, Fig. 6e).

Immune stimulation of PbA-infected mice with Pool or T2 strategies induced comparable increases in the frequencies of splenic B cells, Tregs (Extended data, Fig.6a,b,e), effector/effector memory CD4 T cells and central memory CD8 T cells (Extended data, Fig.7a,c,g), and reduction in the frequencies of total CD8 T cells when compared to non-immune stimulated infected mice (Extended data, Fig. 6a,d).

In summary, immunological analysis demonstrated that, independently of the health status of the mice, immune stimulation with type 2 immunogens reduces the frequency of CD8 T cells and increases the percentage of Treg cells in the spleen, as well as the serum level of IL-10.

Taken together, our data point to a positive influence of immune responses induced by strategies involving type 2 stimuli on the long-term memory of healthy mice, confirm our previous demonstration of late neurocognitive behavioural dysfunction following a single episode of non-severe malaria, and indicate a recovering effect of this deficit exerted by immune stimulation with type 2 immunogens subsequent to infection. 


\section{DISCUSSION}

Here, we describe for the first time a beneficial modulatory effect of immune stimulation on cognition in healthy adult mice. Our findings show a clear positive effect of immune stimuli, specifically triggered by immunization strategies involving type-2 immunogens, on long-term memory, as verified by the 'new object recognition task' (NORT), a robust and frequently used behavioural task for the analysis of recognition memory in mice ${ }^{51}$.

We have previously identified cognitive-behavioural impairment as late sequelae of a single non-severe malaria episode, using the classical ECM model with treatment of animals before the presentation of neurological signs or cerebrovascular damage ${ }^{32,52}$. We propose that this model is appropriate for the study of non-severe Plasmodium falciparum malaria ${ }^{28}$, as both parasite-host pairs involve the potentiality of $\mathrm{CM}$ development that can be avoided with timely drug treatment.

The data described here confirm our previous work, showing that neurological impairment can occur even in the absence of classical clinical signs of $\mathrm{CM}^{32}$. We propose, therefore, that the term "non-severe malaria" should be used, preferentially to the classical expression "non-cerebral malaria", to describe the experimental model or the human situation in which clinical signs of CM are not observable. In agreement with our observation is the activation of microglia at day 4 post-infection, before the overwhelming cerebral inflammation and development of the clinical signs of $\mathrm{CM}^{53}$. The levels of proinflammatory cytokines also increase around 3-4 days after $P$. berghei ANKA infection in $\mathrm{C} 75 \mathrm{BL} / 6$ mice $^{54,55}$. It is possible, therefore, that the late cognitive deficit observed in our studies results from the early activation of immune cells in the central nervous system (CNS).

Remarkably, we observed a positive effect of immune stimulation on reversing the cognitive-behavioural impairment associated with non-severe malaria. Mice treated with CQ four days after infection by $P$. berghei ANKA and immune stimulated with T2 and Pool strategies did not present the deficit of object recognition recorded after infection without subsequent immune stimulation. We also observed reversal of anxiety-like behaviour in a light-dark task, following immune stimulation of infected mice. Recent data from our laboratory shows that these behavioural changes are observable as early as 12 days subsequent to malaria treatment (data not shown), pointing to a reversible potential effect of the immune stimuli.

The CNS and the immune system interact under homeostatic conditions and a wellbalanced immune response is needed for a proper function of the $\mathrm{CNS}^{6-7}$. T cells are essential for normal neurogenesis and cognition ${ }^{6,56-58}$.

Communication between peripheral immune cells and CNS takes place in the brain, probably at the meningeal spaces ${ }^{6}$, where T cells influence the CNS via the production of cytokines. It has been shown that proinflammatory cytokines impair cerebral function and cognition at high pathological concentration, as during infections ${ }^{6}$. An exacerbated peripheral inflammatory response may cause M1 microglial activation and provoke the production of proinflammatory cytokines such as TNF- $\alpha$ and IL1- $\beta$ that may impair cognitive function ${ }^{59}$. Elevated levels of anti-inflammatory/regulatory cytokines such as 
286 IL-4 and IL-10 may have the opposite effect, inducing M2 microglial activation and positively influencing cognition ${ }^{60-62}$.

Treg cells are a subset of $\mathrm{T}$ cells with immunomodulatory function, important for immune and neuronal homeostasis under physiological conditions, and for the control of pathological immune responses ${ }^{63-66}$. They perform their function mainly via secretion of IL-10 and TGF $\beta$, anti-inflammatory/regulatory cytokines ${ }^{63-66}$. After ischemic brain stroke, there is massive accumulation of Treg cells in the mouse brain ${ }^{67}$, where they decrease inflammatory cell infiltration and microglia activation, antagonize the production of proinflammatory cytokines and, consequently, reduce brain damage through a mechanism involving IL-10 secretion ${ }^{68}$. The neuroprotective activity of Treg cells has also been described in murine models of Parkinson's disease, HIV-1associated neurodegeneration and amyotrophic lateral sclerosis ${ }^{69-72}$.

In this study, healthy and infected-mice stimulated with strategies involving type 2 immunogens (Pool and T2 groups) significantly increased the number of splenic Treg cells and IL-10 level in the serum. Considering that Treg cells and IL-10 can restrict neuroinflammation ${ }^{71-76}$, it is reasonable to assume that the immunization strategies used likely improve cognitive function by promoting a balanced cross-talk between the immune system and the CNS mediated through Treg cells and IL-10. The mechanism by which immune stimulation with type-2 immunogens benefits cognition is presently under investigation.

The results reported here may offer a new paradigm for the design of memory improvement strategies. Our data suggest that vaccination procedures may provide benefits additional to the prevention of infection, offering a potential approach for boosting cognition function in healthy individuals, and in helping the recovery of those whose cognition may have been impaired by chronic and infectious diseases, including malaria, and by the effects of ageing.

\section{REFERENCES}

1. Jerne NK. Idiotypic networks theory and other preconceived ideas. Immunol Rev. 1984;79:5-24.

2. Cohen, IR. The cognitive paradigm and the immunological homunculus. Immunol Today. 1992;13(12):490-4.

3. Cohen IR. Discrimination and dialogue in the immune system. Semin Immunol. 2000;12(3):215-9.

4. Daniel-Ribeiro CT, Martins YC. Imagens, Micróbios e Espelhos: os sistemas imune e nervoso e nossa relação com o ambiente. Rio de Janeiro: Ed. Fiocruz. 2017;3:161-162.

5. Kivisakk P, Imitola J, Rasmussen S, Elyaman W, Zhu B, Ransohoff RM, et al. Localizing central nervous system immune surveillance: meningeal antigen presenting cells activate $\mathrm{T}$ cells during experimental autoimmune encephalomyelitis. Ann Neurol. 2009;65(4):457-469. 
6. Kipnis J, Gadini S, Derecki N. Pro-cognitive properties of T cells. Nat Rev Immunol. 2012;12(9):663-669.

7. Nataf S. Autoimmunity as a Driving Force of Cognitive Evolution. Front Neurosci. 2017;11:582.

8. Schwartzer JJ, Careaga M, Coburn MA, Rose DR, Hughes HK, Ashwood P. Behavioral impact of maternal allergic-asthma in two genetically distinct mouse strains. Brain Behav Immun. 2017;63:99-107.

9. Mueller FS, Polesel M, Richetto J, Meyer U, Weber-Stadlbauer U. Mouse models of maternal immune activation: Mind your caging system! Brain Behav Immun. 2018;73:643-660.

10. Yang J, Qi F, Gu H, Zou J, Yang Y, Yuan Q et al. Neonatal BCG vaccination of mice improves neurogenesis and behavior in early life. Brain Res Bull. 2016;120:25-33.

11. Bossu P, Cutuli D, Palladino I, Caporali P, Angelucci F, Laricchiuta D et. al. A single intraperitoneal injection of endotoxin in rats induces long-lasting modifications in behavior and brain protein levels of TNF- $\alpha$ and IL-18. J Neuroinflammation. 2012;9:101.

12. Depino AM. Early prenatal exposure to LPS results in anxiety- and depression-related behaviors in adulthood. Neuroscience. 2015;299:56-65.

13. Kannan G, Pletnikov MV. Toxoplasma gondii and Cognitive Deficits in Schizophrenia: An Animal Model Perspective. Schizoph Bull. 2012;38(6):1155-1161.

14. Iqbal J, Mueller U. Virus infection causes specific learning deficits in honeybee foragers. Proc Biol Sci. 2007;274:1517-1521.

15. Odera VM, Snow RW, Newton CRJC. The burden of the neurocognitive impairment associated with Plasmodium falciparum malaria in sub-Saharan Africa. Am J Trop Med Hyg. 2004;71(2 Suppl):64-70.

16. Carter JA, Lees JA, Gona JK, Murira G, Rimba K, Neville BGR et al. Severe falciparum malaria and acquired childhood language disorder. Dev Med Child Neurol. 2006;48(1):51-7.

17. Boivin MJ, Bangirana $P$, Byarugaba J, Opoka RO, Idro R, Jurek AM et al. Cognitive impairment after cerebral malaria in children: a prospective study. Pediatrics. 2007;119(2):e360-6.

18. John CC, Bangirana P, Byarugaba J, Opoka RO, Idro R, Jurek AM et al. Cerebral malaria in children is associated with long-term cognitive impairment. Pediatrics. 2008;122(1):e92-9.

19. Kihara M, Carter JA, Holding PA, Vargha-Khadem F, Scott RC, Idro R et al. Impaired everyday memory associated with encephalopathy of severe malaria: the role of seizures and hippocampal damage. Malar J. 2009;8:273. 20. Holmberg D, Franzén- Rohl E, Idro R, Opoka RO, Bangirana P, Sellgren CM et. al. Cerebrospinal fuid kynurenine and kynurenic acid concentrations are associated with coma duration and long-term neurocognitive impairment in Ugandan children with cerebral malaria. Malar J. 2017;16(1):303. 
21. Thuilliez J, Sissoko MS, Toure OB, Kamate P, Berthelemy JC, Doumbo OK. Malaria and primary education in Mali: a longitudinal study in the village of Donéguébougou. Soc Sci Med. 2010;71(2):324-34.

22. Bangirana $P$, Allebeck $P$, Boivin MJ, John CC, Page C, Ehnvall A, et al. Cognition, behaviour and academic skills after cognitive rehabilitation in Uganda children surviving severe malaria: a randomised trial. BMC Neurol. 2011;11:96.

23. Fink G, Olgiati A, Hawela M, Miller JM, Matafwali B. Association between early childhood exposure to malaria and children's pre-school development evidence from Zambia early childhood development project. Malar J. 2013;12:12.

24. Vorasan N, Pan-Ngum W, Jittamala P, Maneeboonyang W, Rukmanee P, Lawpoolsri S. Long-term impact of the childhood malaria infection on school performance among school children in a malaria endemic area along the Thai-Myanmar border. Malar J. 2015;14:401.

25. Reverchon F, Mortaud S, Sivoyon M, Maillet I, Laugeray A, Palomo J et. al. IL-33 receptor ST2 regulates the cognitive impairments associated with experimental cerebral malaria. PloS Pathog. 2017;13(4):e1006322.

26. Desruisseaux MS, Gulinello M, Smith DN, Lee SC, Tsuji M, Weiss LM et al. Cognitive dysfunction in mice infected with Plasmodium berghei strain ANKA. J Infect Dis. 2008;197(11):1621-7.

27. Reis PA, Comim CM, Hermani F, Silva B, Barichello T, Portella AC et al. Cognitive dysfunction is sustained after rescue therapy in experimental cerebral malaria, and is reduced by additive antioxidant therapy. PloS Pathog. 2010;6(6):e1000963.

28. World Health Organization. World Malaria Report. Geneva: WHO; 2019.

29. Fernando SD, Gunawardena DM, Bandara MRSS, De Silva D, Carter R, Mendis $\mathrm{KN}$ et al. The impact of repeated malaria attacks on the school performance of children. Am J Trop Med Hyg. 2003;69(6):582-8.

30. Vitor-Silva S, Reyes-Lecca RC, Pinheiro TRA, Lacerda MVG. Malaria is associated with poor school performance in endemic area of the Brazilian Amazon. Malar J. 2009;8:230.

31. Tapajós R, Castro D, Melo G, Balogun S, James M, Pessoa R et al. Malaria impact on cognitive function of children in a peri-urban community in the Brazilian Amazon. Malar J. 2019;18(1):173.

32. de Sousa LP, Almeida RF, Ribeiro-Gomes FL, Carvalho LJM, Souza TM, Souza DOG \& Daniel-Ribeiro CT. Long-term effect of uncomplicated Plasmodium berghei ANKA malaria on memory and anxiety-like behaviour in C57BL/6 mice. Parasit Vectors. 2018;11(1):191.

33. Lavigne MV, Castro M, Mateo N, Deluchi S, Atzori C, Piudo L et al. Wholecell Bordetella pertussis vaccine component modulates the mouse immune response to an unrelated soluble antigen. Microbes Infect. 2002;4(8)815820. 
34. Castilho SF, Chovel ML, Hernández NG, González LC, Blanco A, Hernández DS et al. A Bordetella pertussis proteoliposome induces protection in mice without affecting the immunogenicity of diphtheria and tetanus toxoids in a trivalent formulation. Clin Exp Vaccine Res. 2016;5(2):175-178.

35. Goodier MR, Rodriguez-Galan A, Lusa C, Nielsen CM, Darboe A, Moldoveanu AL et al. Influenza Vaccination Generates Cytokine-Induced Memory-like NK Cells: Impact of Human Cytomegalovirus Infection. J Immunol. 2016;197(1):313-325.

36. Zhu W, Li S, Wang C, Yu G, Prausnitz MR, Wang BZ. Enhanced immune responses conferring cross-Protection by skin Vaccination With a Tricomponent influenza Vaccine Using a Microneedle Patch. Front Immunol. 2018:9:1705.

37. Brahimi K, Pérignon JL, Bossus M, Gras H, Tartar A, Druilhe P. Fast immunopurification of small amounts of specific antibodies on peptides bound to ELISA plates. J Immunol Methods. 1993;162(1):69-75.

38. Oeuvray C, Bouharoun-Tayoun H, Grass-Masse H, Lepers JP, Ralamboranto L, Tartar A et al. A novel merozoite surface antigen of Plasmodium falciparum (MSP-3) identified by cellular-antibody cooperative mechanism antigenicity and biological activity of antibodies. Mem Inst Oswaldo Cruz. 1994;89(2):7780.

39. Daher LJ, Demanga CG, Prieur E, Pérignon JL, Bouharoun-Tayoun H, Druilhe $P$. Toward the rational design of a malaria vaccine construct using the MSP3 family as an example: contribution of immunogenicity studies in models. Infect Immun. 2010;78(1):477-485.

40. Matos DCS, Marcovistz R, Cabello PH, Georgini AR, Sakauchi D, Silva LL. Immunogenicity Test of Tetanus Component in Adsorbed Vaccines by Toxin Binding Inhibition Test. Mem Inst Oswaldo Cruz. 2002;97(6):909-913.

41. Lima MCR, Prouvost-Danon A, Patricia MR, Chagas MS, Calheiros AS, Cordeiro RSB. Studies on the mechanisms involved in antigen-evoked pleural inflammation in rats: contribution of $\operatorname{lgE}$ and complement. J Leukoc Biol. 1997;61(3):286-292.

42. Comoy EE, Capron A, Thyphronitis G. In vivo induction of type 1 and 2 immune responses against protein antigens. Int Immunol. 1997;9(4):523531.

43. Terhune TD, Deth RC. Aluminum Adjuvant-Containing Vaccines in the Context of the Hygiene Hypothesis: A Risk Factor for Eosinophilia and Allergy in a Genetically Susceptible Subpopulation? Int J Environ Res Public Health. 2018;15(5):901.

44. Bosmann M, Russkampa NF, Warda PA. Fingerprinting of the TLR4-induced acute inflammatory response. Exp Mol Pathol. 2012;93(3):319-323.

45. Kozyreva VS, Subbotovskaia AI, Shilova AN, Karpenko AA. Immunological aspects of formation of restenoses after endothelial lesions. Angiol Sosud Khir. 2014;20(1):21-26. 
46. Couch Y, Trofimov A, Markova N, Nikolenko V, Steinbusch HW, Chekhonin $\checkmark$ et al. Low-dose lipopolysaccharide (LPS) inhibits aggressive and augments depressive behaviours in a chronic mild stress model in mice. $J$ Neuroinflammation. 2016;13(1):108.

47. Fontana MF, Baccarella A, Kellar D, Oniskey TK, Terinate P, Rosenberg SD et. al. Myeloid expression of the AP-1 transcription factor JUNB modulates outcomes of type 1 and type 2 parasitic infections. Parasite Immunol. 2015;37(9):470-478.

48. Almeida RF, Ganzella M, Machado DG, Loureiro SO, Leffa D, QuiconzesSantos $\mathrm{A}$ et al. Olfactory bulbectomy in mice triggers transient and longlasting behavioural impairments and biochemical hippocampal disturbances. Prog Neuropsychopharmacol Biol Psychiatry. 2017;76:1-11.

49. Figueiredo CP, Clarke JR, Ledo JH, Ribeiro FC, Costa CV, Melo HM et al. Memantine rescues transient cognitive impairment caused by highmolecularweight $a \beta$ oligomers but not the persistent impairment induced by lowmolecular-weight oligomers. J Neurosci. 2013;33(23):9626-34.

50. Maheshwari SC, Sbarma SB, Ahujat S, Saxena SN. Development of a mouse model to estimate the potency of the diphtheria toxoid component of diphtheria-tetanus and diphtheria-tetanus-pertussis vaccines. J Biol Stand. 1988;16(3):139-146.

51. Leger M, Quiedeville A, Bouet V, Haelewyn B, Boulouard M, Schumann-Bard $P$ et al. Object recognition test in mice. Nat Protoc. 2013;8(12):2531-2537.

52. Potter S, Chan-Ling T, Ball HJ, Mansour H, Mitchell A, Maluish L, et al. Perforin mediated apoptosis of cerebral microvascular endotelial cells during experimental cerebral malaria. Int J Parasitol. 2006;36(4):485-496.

53. Pais TF, Chatterjee $S$. Brain macrophage activation in murine cerebral malaria precedes accumulation of leukocytes and CD8+ T cell proliferation. J Neuroimmunol. 2005;163(1-2):73-83.

54. Hanum S, Hayano M, Kojima S. Cytokine and chemokine responses in a cerebral malaria-susceptible or-resistant strain of mice to Plasmodium berghei ANKA infection: early chemokine expression in the brain. Int Immunol. 2003;15(5):633-640.

55. Hansen DS, Siomos MA, Buckingham L, Scalzo AA, Schofield L. Regulation of Murine Cerebral Malaria Pathogenesis by CD1d-Restricted NKT Cells and the Natural Killer Complex. Immunity. 2003;18(3):391-402.

56. Ziv Y, Ron N, Butovsky O, Landa G, Sudai E, Greenberg N et al. Immune cells contribute to the maintenance of neurogenesis and spatial learning abilities in adulthood. Nat Neurosci. 2006;9(2):268-275.

57. Baruch K, Schwartz M. CNS-specific T cells shape brain function via the choroid plexus. Brain Behav Immun. 2013;34:11-16.

58. Radjavi A, Smirnov I, Kipnis J. Brain antigen-reactive CD4+ T cells are sufficient to support learning behavior in mice with limited $T$ cell repertoire. Brain Behav Immun. 2014;35:58-63. 
59. Hoogland ICM, Houbolt C, Westerloo DJV, Gool WAV and Beek DV. Systemic inflammation and microglial activation: systematic review of animal experiments. J Neuroinflammation. 2015;12:114.

60. Derecki NC, Cardani AN, Yang CH, Quinnies KM, Crihfield A, Lynch KR et al. Regulation of learning and memory by meningeal immunity: a key role for IL-4. J Exp Med. 2010;207(5):1067-1080.

61. Tang $\mathrm{Y}$, Le W. Differential Roles of $\mathrm{M} 1$ and $\mathrm{M} 2$ Microglia in Neurodegenerative Diseases. Mol Neurobiol. 2016;53(2):1181-1194.

62. Qi F, Zuo Z, Yang J, Hu S, Yang Y, Yuan Q et al. Combined effect of BCG vaccination and enriched environment promote neurogenesis and spatial cognition via a shift in meningeal macrophage M2 polarization. J Neuroinflammation. 2017;14(1):32.

63. O'Garra A, Vieira P. Regulatory T cells and mechanisms of immune system control. Nat Med. 2004;10(8):801-805.

64. Anderson KM, Olson KE, Estes KA, Flanagan K, Gendelman HE, Mosley RL. Dual destructive and protective roles of adaptive immunity in neurodegenerative disorders. TransI Neurodegener. 2014;3(1):25.

65. Panduro M, Benoist C, Mathis D. Tissue Tregs. Annu Rev Immunol. 2016; $34: 609-633$.

66. Evans FL, Dittmer M, de la Fuente AG, Fitzgerald DC. Protective and Regenerative Roles of T Cells in Central Nervous System Disorders. Front Immunol. 2019;10:2171.

67. Ito M, Komai K, Mise-Omata S, lizuka-Koga M, Noguchi Y, Kondo T et al. Brain regulatory $T$ cells suppress astrogliosis and potentiate neurological recovery. Nature. 2019;565(7738):246-250.

68. Liesz A, Suri-Payer E, Veltkamp C, Doerr H, Sommer C, Rivest S et al. Regulatory $\mathrm{T}$ cells are key cerebroprotective immunomodulators in acute experimental stroke. Nat Med. 2009;15(2):192-199.

69. Reynolds AD, Banerjee R, Liu J, Gendelman HE, Mosley RL. Neuroprotective activities of CD4+CD25+ regulatory $T$ cells in an animal model of Parkinson's disease. J Leukoc Biol. 2007;82(5):1083-1094.

70. Banerjee R, Mosley RL, Reynolds AD, Dhar A, Jackson-Lewis V, Gordon PH et al. Adaptive immune neuroprotection in G93ASOD1 amyotrophic lateral sclerosis mice. PLoS One. 2008;3(7):e2740.

71. Liu J, Gong N, Huang X, Reynolds AD, Mosley RL, Gendelman HE. Neuromodulatory activities of CD4+CD25+ regulatory $T$ cells in a murine model of HIV-1-associated neurodegeneration. J Immunol. 2009;182(6):3855-3865.

72. Liesz A, Suri-Payer E, Veltkamp C, Doerr H, Sommer C, Rivest S et al. Regulatory $\mathrm{T}$ cells are key cerebroprotective immunomodulators in acute experimental stroke. Nat Med. 2009;15(2):192-199.

73. Reynolds AD, Stone DK, Hutter JA, Benner EJ, Mosley RL, Gendelman HE. Regulatory $T$ cells attenuate Th17 cell-mediated nigrostriatal dopaminergic 
neurodegeneration in a model of Parkinson's disease. J Immunol. 2010;184(5):2261-2271.

74. Kelly LD, Li X, Kilday C, Feldman S, Clark S, Liu F et al. Increased circulating regulatory $\mathrm{T}$ cells in medicated people with schizophrenia. Psychiatry Res. 2018;269:517-523.

75. Ito M, Komai K, Mise-Omata S, lizuka-Koga M, Noguchi Y, Kondo T et al. Brain regulatory $T$ cells suppress astrogliosis and potentiate neurological recovery. Nature. 2019;565(7738):246-250.

76. Machhi J, Kevadiya BD, Muhammad IJ, Herskovitz J, Olson KE, Mosley RL et al. Harnessing regulatory $T$ cell neuroprotective activities for treatment of neurodegenerative disorders. Mol Neurodegener. 2020;15(1):32.

\section{ACKNOWLEDGEMENTS}

LPS is grateful to the Programa de Pós-Graduação em Biologia Parasitária of Instituto Oswaldo Cruz (IOC), Fundação Oswaldo Cruz (Fiocruz) for the Doctoral fellowship. The authors are grateful to Professor Richard Culleton for his kindness carefully reading the final version of this manuscript and for the valuable comments and suggestions for the improvement of the text. We do also thank Doctor Leonardo Carvalho for his critical review and welcome discussions. We are indebt to the Laboratório de Inflamação (Dr. Marco Aurélio Martins and Dr. Tatiana Ferreira), Laboratório de Pesquisa em Malária (Luana santos and Thalita Ferraz), Laboratório de Pesquisa sobre o Timo of the IOC-Fiocruz (Dr. Daniella Mendes Arêas and Dr. Dyna Raposo) of IOC; Biomanguinhos (Dr. Maria de Lourdes de Sousa Maia, Alessandro Fonseca, Camilla Bayma and Dr. Denise Cristina Matos) and Farmanguinhos (Dr. Márcia Coronha Ramos Lima and Dr. Andréa Luca) of Fiocruz and Instituto Butantan (Dr. Jorge Kalil and Dr. Paulo Lee Ho and Aline Abrantes) and Vac4all (Dr. Pierre Duiilhe) for reagent supply and study of the immune responses to vaccines.

\section{FUNDING}

The work received financial support from the Instituto Oswaldo Cruz's POM, Fiocruz. This work is part of LPS's PhD research supported by Capes (Brazil) and by Faperj (RJ, Brazil) fellowships. GLW, DOS and CTDR are supported by $C N P q$, Brazil, through a Productivity Research Fellowship and GLW and CTDR are "Cientistas do Nosso Estado" recognized by the Faperj. The Laboratório de Pesquisa em Malária (LPM), IOC, Fiocruz and the Departamento de Bioquímica of the Universidade Federal do Rio Grande do Sul are National Institutes of Science \& Technology (INCT) Associated Laboratories. The LPM is also an Associated Laboratory of the Neuroinflammation Network of the Faperj.

\section{AUTHOR CONTRIBUTIONS}

LPS was responsible for the realization of all experiments (including infection and treatment; immune stimulation, and conduction, observation and data 
593 collection/systematisation of cognitive tests and immune response analyses in mice), 594 helped in the analysis and interpretation of tests and drafted the manuscript. FLRG followed all stages of the experiment, realization of experiments, discussed the protocols and the project, was in charge of the analysis and discussion of immune response data and helped in drafting the manuscript. RFA and TMS helped in systematization of data concerning behavioural tests and analysed and interpreted the cognitive data. GW proposed the statistical analyses of the data and was responsible for them. DOS discussed the project since its conception and helped in designing the experiments. CTDR is responsible for conception and design of the study, and helped in data analysis, interpretation and drafting and finalizing the manuscript together with LPSV and FLRG. All authors read, reviewed and approved the final manuscript.

604

605

606

607

608

609

610

COMPETING INTERESTS

The authors declare that they have no competing interests.

\section{METHODS}

Mice and Parasite. The Instituto de Ciência e Tecnologia em Biomodelos of the 613 Fundação Oswaldo Cruz (ICTB- Fiocruz, Brazil) provided seven-week-old C57BL/6 614 female mice weighing 20-25 g. Mice were housed in racks with an air filtration system 615 in a room maintained at $25^{\circ} \mathrm{C}$ and light/dark cycles of 12 hours in cages containing five animals with free acquisition to food and water. All procedures were carried out in accordance with animal welfare approved by the Ethical Committee on the Use of Laboratory Animals of Instituto Oswaldo Cruz under CEUA-IOC: L-010/2015 concession. Plasmodium berghei ANKA (PbA) infections were carried out using a stable transfected strain of $P b A$ expressing a green fluorescent protein (PbA-GFP) generated as described previously ${ }^{1}$.

623

Infection and treatment of experimental groups. C57BL/6 mice were infected intraperitoneally (ip) with $150 \mu \mathrm{l}$ of PbA-infected red blood cells, cryopreserved and thawed. Five days after infection, the total blood was collected, adjusted to $1 \times 10^{6}$ parasitized erythrocytes in $100 \mu \mathrm{l}$ of PBS and injected ip to C57BL/6 mice from the experimental groups. Parasitaemia was monitored by flow cytometry, based on the percentage of $\mathrm{GFP}^{+}$erythrocytes. In this experimental model, the establishment of cerebral malaria (CM) occurs between the fifth and sixth day of infection ${ }^{2}$. In this study, mice were treated on the fourth day of infection (mean parasitaemia $2.5 \%$ ) with 25 $\mathrm{mg} / \mathrm{kg}$ of chloroquine (CQ) by gavage for seven days ${ }^{3}$, before any clinical sign of $\mathrm{CM}$. All groups were similarly manipulated. Experiments carried out with groups of uninfected mice treated with CQ or not (control group received PBS) have previously shown that the CQ treatment did not influence the performance in behavioural tasks and anxiety phenotype ${ }^{4}$.

Experimental Description. C57BL/6 mice were divided into groups of PbA-infected and Control animals (non-infected) and both were treated with chloroquine (CQ) for seven days from the fourth day of infection. Thirteen days after treatment, mice from respective groups were subdivided into non-immune stimulated and immune stimulated groups (Fig. 1). The following vaccines and antigens were used for immune 
642 stimulation: Diphtheria and Tetanus toxoids (dT) vaccine for adults, Influenza vaccine, 643 Plasmodium falciparum Merozoite Surface Protein 3 (PfMSP-3 recombinant protein), 644 White chicken egg ovalbumin (OVA) and Lipopolysaccharide of Escherichia coli (ECLPS). Three different immune stimulation strategies were performed: a combination of all antigens and vaccines described above (from here now, called Pool); a combination of antigens and vaccines (Influenza vaccine and EcLPS) that trigger, preferentially, a type 1 pattern of immune response (from here now, denominated T1); and a combination of antigens and vaccines (dT vaccine, PfMSP-3 recombinant protein and OVA) that trigger, preferentially, a type 2 pattern of immune response (from here now, called T2). The groups of mice were denominated: Control (non-infected / non-immune stimulated); Pool (non-infected / Pool-immune stimulated); T1 (noninfected / T1-Immune stimulated); T2 (non-infected / immune stimulated); Inf (infected / non-immune stimulated); Inf-Pool (infected / Pool-immune stimulated); T1 (infected / T1-immune stimulated) and T2 (infected / T2-immune stimulated). All control groups were treated as the experimental groups: they were age-matched, mock-immune stimulated, mock-infected, and treated with $\mathrm{CQ}$ whenever appropriate. Subsequently, mice behavioural performance was assessed by Open Field Test (OFT), Novel Object Recognition Test (NORT) and Light-Dark (Fig. 1). About 300 mice were used for these experimental strategies in five consecutive sessions.

661

Immune system stimuli. The immune stimulation was initiated fourteen days after the

662 end of $\mathrm{CQ}$ treatment, being performed in the course of the following sixty-two days

663 (Fig. 1). Antigens and/or vaccines were administered by different routes and in different regions of the animal's body (Table 1). The doses administrated were defined based on dose-response protocols available in the literature capable of stimulating the murine immune system without imparting risk of death to mice immune stimulated ${ }^{5-12}$.

667

Immune stimulation with Plasmodium falciparum Merozoite Surface Protein 3 (PfMSP3 recombinant protein). The mice were challenged with $10 \mu \mathrm{g}$ of PfMSP-3/mice recombinant protein (in collaboration with Clinical Trials of Malaria Vaccines (Vac4All Initiative), Paris, France) adsorbed on 70\% adjuvant solution MONTANIDETM ISA 50 V2 W / O (SEPPIC. Air Liquide - Healthcare), in $100 \mu$ l of PBS. Three subcutaneous injection were performed at the tail region with a twenty-day interval between immune stimulations $^{9-10}$ (Fig. 1, Table 1).

Immune stimulation with Tetanus-Diphtheria and Influenza Vaccines. The vaccines used in this study were: Tetanus-Diphtheria (dT) double bacterial (Biological E Limited - BE, Telangana - India, Lot. 34005815), in collaboration with the Division of Health Surveillance - CAP 3.1 of the Fundação Oswaldo Cruz (Rio de Janeiro, Brazil); and Trivalent Influenza granted by the Technological Development and Production Division of Instituto Butantan (São Paulo, Brazil, Lot. 160034). Mice received $100 \mu \mathrm{l}(1 / 5$ of the human dose) of dT and Influenza vaccines by subcutaneous (dorsal region) and intramuscular (left quadriceps region) routes, respectively (Table 1). Three inoculations with a twenty-day interval between immune stimulations were performed ${ }^{5-6}$ (Fig. 1). chicken egg ovalbumin (SIGMA-ALDERICH, Cod. A5503-50g) adsorbed onto 688 aluminum hydroxide [Al $(\mathrm{OH}) 3]$ in a final volume of $200 \mu \mathrm{l}$ per animal in three 689 inoculations. The first inoculation was performed at the dorsal region by subcutaneous 
690 injection and the following (second and third inoculation) by ip route (Table 1) with six 691 days between them ${ }^{11}$ (Fig. 1).

692

693

694

695

696

697

698

699

700

701

702

703

704

705

706

707

708

709

710

711

712

713

714

715

716

717

718

719

720

721

722

723

724

725

726

727

728

729

730

731

732

733

734

735

736

737

Immune stimulation with Lipopolysaccharide from Escherichia coli (EcLPS). Mice were challenged with $0.1 \mathrm{mg} / \mathrm{kg}$ of ECLPS 0111: B4 (SIGMA-ALDERICH, L2630-10MG, Lot 025M4040V12140701) diluted in phosphate-buffered saline (PBS). Two ip inoculations were performed (Table 1) with a range of nine days between the immune stimulations ${ }^{12}$ (Fig. 1).

Evaluation of the immune response. Following stimulation of the immune system, mice were randomly selected and sacrificed for individual withdrawal of whole blood, via cardiac puncture, and spleen at day 84 after the end of $C Q$ treatment. Serum samples were preserved at $-70{ }^{\circ} \mathrm{C}$. Total $\operatorname{lgG}$ antibody response to PAMSP-3 recombinant protein, Tetanus-Diphtheria toxoids (dT) and Influenza vaccines; the serum cytokine profile; the splenic lymphocyte subpopulations; and the response to Ovalbumin sensitization were evaluated.

Specific antibody responses. The antibody response against PfMSP-3 recombinant protein and Influenza vaccine were determinate by conventional Enzyme-Linked immunosorbent Assay - ELISA ${ }^{9-10}$, and the antibody response against dT vaccine was determined by Toxin Binding Inhibition - $\mathrm{ToBI}^{13}$.

Cytokine profile. Cytokines in the serum samples were measured with Cytometric Bead Array (CBA) Mouse Th1/Th2/Th17 (BD Biosciences) according to the manufacturer instructions. The data were collected on the BD FACSCANTO II flow cytometer and analysed by FCAP Array ${ }^{\mathrm{TM}}$ Software (BD Bioscience).

Splenic lymphocyte subpopulations. Individual spleens were removed and mechanically dissociated using a syringe plunger above $70 \mu \mathrm{m}$-pore size Falcon cell strainer (BD Biosciences). Red blood cells were lysed using ACK lysing buffer (Sigma). Single-cell suspensions were counted and incubated with anti-Fcy III/II (CD16/32) receptor $\mathrm{Ab}$ (2.4G2) in PBS containing 3\% FCS for $15 \mathrm{~min}$, and immunolabelled for 30 min at $4^{\circ} \mathrm{C}$ in the dark with the following fluorochrome-conjugated antibodies: PE-Cy 7 anti-mouse CD8 (53-6.7), PerCP-Cy5.5 anti-CD3 (145-2c11), APC-H7 anti-mouse CD4 (GK1.5), APC anti-mouse B220 (RA3-6B2), BB515 anti-mouse CD62L (MEL14), APC anti-mouse CD44 (IM7) and/or PE anti-mouse CD25 (7D4). For Treg cells analyses, cells were fixed and permeabilized, after staining for surface markers, with eBioscience $^{\mathrm{TM}}$ Foxp3/Transcription Factor Staining Buffer Set according to the manufacturer instructions and incubated with the antibody Alexa Flour 647 anti-Foxp3 (R16715). All antibodies were from BD Biosciences. Data were collected using FACSDiva software on a FACSCANTO II flow cytometer (BD Biosciences), and analysed using FlowJo software (TreeStar).

Intradermal skin test. In the footpad of the left paw, $3 \mu \mathrm{g}$ of OVA, diluted in $30 \mu \mathrm{l}$ of PBS, were injected in each animal. After 30 minutes, the plantar thickness $(\mathrm{mm})$ was measured using a digital caliper. Oedema formation was expressed as the difference of the pad thickness measured before and after the inoculation of OVA ${ }^{11}$. 
738 Behavioral analysis. The schedule of the behavioral tasks is shown in Methods Fig.

739 1. Mice were individually submitted to different behavioral paradigms to evaluate their

740 exploratory and locomotor activity, cognitive abilities, and parameters involved in 741 anxiety-like behavior from day 88 to 92 post-infection ( 77 to 81 days after the complete parasitological cure of animals obtained with $\mathrm{CQ}$ treatment). The beginning of behavioral tests corresponded to 22 days after the last stimulation with PAMSP-3 recombinant protein, Tetanus-Diphtheria, and Influenza vaccines, 7 days after the last injection of ovalbumin, and three days after the LPS final inoculation. The same cohort of mice was used in all tasks (Methods Fig. 1). All experiments were carried out with an incandescent light source of 200 lux of intensity in the evening period. Animals were acclimatized in the experimental room at least for 2 hours before the experimental sessions. Behavior was captured by a video camera positioned above the task apparatus. Locomotion in the open field and the object recognition task was analyzed by the AnyMaze ${ }^{\circledR}$ software (Stoelting Co., Wood Dale, IL, USA), while a trained blindto-treatment researcher evaluated other behavioral parameters by video analysis. In all behavioral tests, mice were individually placed on the apparatus, which was previously cleaned with $70 \%$ alcohol and dried.

Open Field Task (OFT). To address the effect of immune stimuli on locomotion and on long-term habituation, mice were individually submitted to the OFT with a training (OFT1) and a test (OFT2) session 24 hours apart, as described elsewhere ${ }^{4}$. In each OFT session, mice were individually allowed to freely explore a grey acrylic square box, dimensions $(50 \times 50 \times 50 \mathrm{~cm}$, length $\times$ width $\times$ height), for 10 minutes. In OFT1, locomotor activity was evaluated during the first three minutes (short-term habituation to novelty) and the last six minutes of the session, and the time and distance traveled in the center zone during the entire session. In OFT2, we evaluated the first three and the last seven minutes of the total distance traveled.

Novel Object Recognition Task (NORT). To evaluate long-term memory for object recognition, the NORT was carried out in the OFT apparatus, 24 hours after its OFT2 session ${ }^{4}$. In the training session, mice were exposed to two identical objects, called familiar objects (FO1 and FO2), for which similar exploratory activity was expected ${ }^{15}$, since they were both novel. The test session was carried out 24 hours later when mice were exposed to a new object (NO) and to one of the previously exposed familiar objects (FO1 or FO2). Memory expression is indicated by the tendency of the animal to spend more time exploring the NO rather that the $\mathrm{FO}^{4,15}$. Animals were individually placed in the periphery of the box with the objects in a session for 10 minutes. Exploration was recorded only when the animals touched the objects, located in opposite and symmetrical corners of the box, with their nose or mouth. The time of exploration of each object was recorded, and its percentage of the time of exploration of both objects was calculated. The object recognition index is calculated as the percentage of time spent on each object (referred to the total time spent on both objects). The difference between the time spent with the NO and the FO is expressed as a delta value obtained with the subtraction of the indexes of each object.

Light/Dark Task. The light/dark task was carried out as described by Almeida et al. ${ }^{16}$ with minor modifications to evaluate the anxiety behavior-like phenotype ${ }^{17}$. The apparatus was a rectangular acrylic box $(50 \times 30 \times 30 \mathrm{~cm}$, height $\times$ length $\times$ width $)$ with two sides colored white and black, separated by a wall $(5 \times 5 \mathrm{~cm})$ with an opening at the 
787 level of the base of the apparatus joining both sides. A white $100 \mathrm{~W}$ lamp, placed $60 \mathrm{~cm}$

788

789

790

791

792

793

794

795

796

797

798

799

800

801

802

803

804

805

806

807

808

809

810

811

812

813

814

815

816

817

818

819

820

821

822

823

824

825

826

827

828

829

830

831

832

above the center of the apparatus, illuminated the white side of the apparatus, while the black side was kept closed without illumination. The mice were individually placed in the light compartment for free exploration of the apparatus for 5 minutes. The following behavioral parameters were analyzed: the time spent in the light compartment and the number of transitions between the compartments (light and dark).

Statistical analysis. All statistical analyses were performed using a statistical software package (Prism 5.0, GraphPad). The data were extracted from the AnyMaze® software. To analyse OFT and Light / Dark task, we used the absolute data. The time in each object in NORT was transformed into a percentage, from which the delta was extracted based on the subtraction: OF1 - OF2 (training session) and NO - FO (test session). The two-way ANOVA with Bonferroni correct were used to analyse OFT. The Student t-test with Mann-Whitney correction were used for to analyse the groups in NORT, light-dark task and immune response. Data are presented as mean \pm standard error. $\mathrm{P}<0.05$ was considered statistically significant.

\section{REFERENCES}

1. Franke-Fayard B, Trueman H, Ramesar J, Mendoza J, Van der Keur M, Van der Linden $\mathrm{R}$ et al. A Plasmodium berghei reference line that constitutively expresses GFP at a high level throughout the complete life cycle. Mol Biochem Parasitol. 2004;137(1):23-33.

2. Potter S, Chan-Ling T, Ball HJ, Mansour H, Mitchell A, Maluish L et al. Perforin mediated apoptosis of cerebral microvascular endotelial cells during experimental cerebral malaria. Int J Parasitol. 2006;36(4):485-96.

3. Reis PA, Comim CM, Hermani F, Silva B, Barichello T, Portella AC et al. Cognitive dysfunction is sustained after rescue therapy in experimental cerebral malaria, and is reduced by additive antioxidant therapy. PloS Pathog. 2010;6(6):e1000963.

4. de Sousa LP, Almeida RF, Ribeiro-Gomes FL, Carvalho LJM, Souza TM, Souza DOG \& Daniel-Ribeiro CT. Long-term effect of uncomplicated Plasmodium berghei ANKA malaria on memory and anxiety-like behaviour in C57BL/6 mice. Parasit Vectors. 2018;11(1):191.

5. Lavigne MV, Castro M, Mateo N, Deluchi S, Atzori C, Piudo L et al. Whole-cell Bordetella pertussis vaccine component modulates the mouse immune response to an unrelated soluble antigen. Microbes Infect. 2002;4(8):815-820.

6. Castilho SF, Chovel ML, Hernández NG, González LC, Blanco A, Hernández DS et al. A Bordetella pertussis proteoliposome induces protection in mice without affecting the immunogenicity of diphtheria and tetanus toxoids in a trivalent formulation. Clin Exp Vaccine Res. 2016; 5(2):175-178.

7. Goodier MR, Rodriguez-Galan A, Lusa C, Nielsen CM, Darboe A, Moldoveanu $\mathrm{AL}$ et al. Influenza Vaccination Generates Cytokine-Induced Memory-like NK Cells: Impact of Human Cytomegalovirus Infection. J Immunol. 2016;197(1):313-325. 
8. Zhu W, Li S, Wang C, Yu G, Prausnitz MR, Wang BZ. Enhanced immune responses conferring cross-protection by skin vaccination with a tri-component influenza vaccine using a microneedle patch. Front Immunol. 2018;9:1705.

9. Oeuvray C, Bouharoun-Tayoun H, Grass-Masse H, Lepers JP, Ralamboranto L, Tartar A et al. A novel merozoite surface antigen of Plasmodium falciparum (MSP-3) identified by cellular-antibody cooperative mechanism antigenicity and biological activity of antibodies. Mem Inst Oswaldo Cruz. 1994;89(2):77-80.

10. Daher LJ, Demanga CG, Prieur E, Pérignon JL, Bouharoun-Tayoun H, Druilhe $P$. Toward the rational design of a malaria vaccine construct using the MSP3 family as an example: contribution of immunogenicity studies in models. Infect Immun. 2010;78(1):477-485.

11. Lima MCR, Prouvost-Danon A, Patricia MR, Chagas MS, Calheiros AS, Cordeiro RS et al. Studies on the mechanisms involved in antigen-evoked pleural inflammation in rats: contribution of IgE and complement. J Leukoc Biol. 1997;61(3):286-292.

12. Couch Y, Trofimov A, Markova N, Nikolenko V, Steinbusch HW, Chekhonin V et al. Low-dose lipopolysaccharide (LPS) inhibits aggressive and augments depressive behaviours in a chronic mild stress model in mice. J Neuroinflammation. 2016;13(1):108.

13. Matos DCS, Marcovistz R, Cabello PH, Georgini AR, Sakauchi D, Silva LL. Immunogenicity Test of Tetanus Component in Adsorbed Vaccines by Toxin Binding Inhibition Test. Mem Inst Oswaldo Cruz. 2002,97(6):909-913.

14. Almeida RF, Ganzella M, Machado DG, Loureiro SO, Leffa D, Quiconzes Santos A, et al. Olfactory bulbectomy in mice triggers transient and longlasting behavioural impairments and biochemical hippocampal disturbances. Prog Neuropsychopharmacol Biol Psychiatry. 2017;76:1-11.

15. Leger M, Quiedeville A, Bouet V, Haelewyn B, Boulouard M, Schumann-Bard P et al. Object recognition test in mice. Nat Protoc. 2013; 8(12):2531-2537.

16. Almeida RF, Comasseto DD, Ramos DB, Hansel G, Zimmer ER, Loureiro SO, et al. Guanosine anxiolytic-like effect involves adenosinergic and glutamatergic neurotransmitter systems. Mol Neurobiol. 2017;54(1):423-436.

17. Griebel G, Holmes A. 50 years of hurdles and hope in anxiolytic drug discovery. Nat Rev Drug Discov. 2013;12(9):667-687. 
870

871

872

Fig. 1
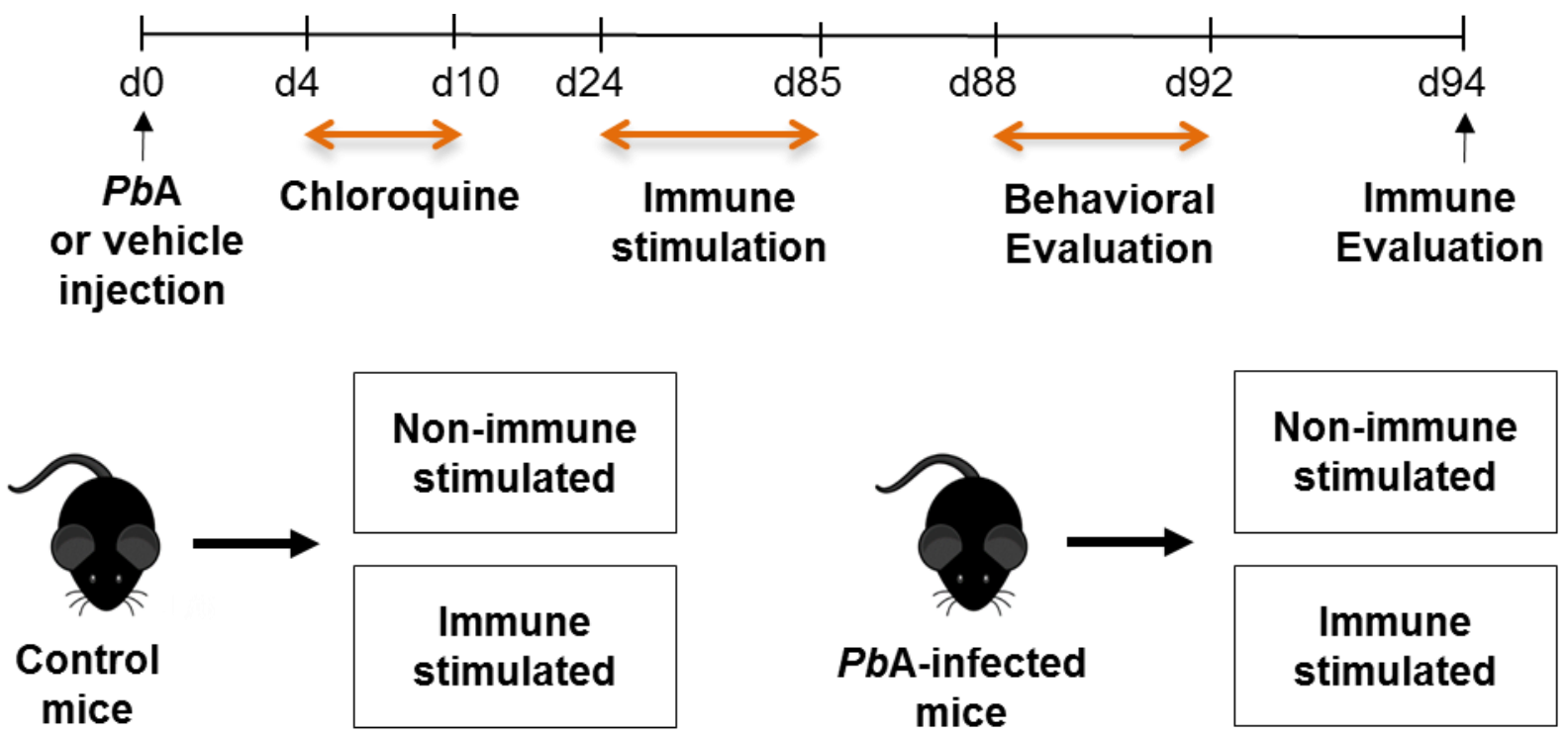

874

875

876

Fig. 1. Groups of mice were infected or not with Plasmodium berghei ANKA $(P b A)$ and treated with chloroquine $(25 \mathrm{mg} / \mathrm{kg}$ ) for seven days via gavage from the fourth day post-infection. After 14 days, the animals were subdivided into groups of mice immune stimulated with different immunization strategies or non-immune stimulated. Subsequently, mice were evaluated in behavioural tasks for locomotivity, memory and

881 anxiety phenotype. The immune response of mice randomly chosen was evaluated. 
883

884

Fig. 2

a

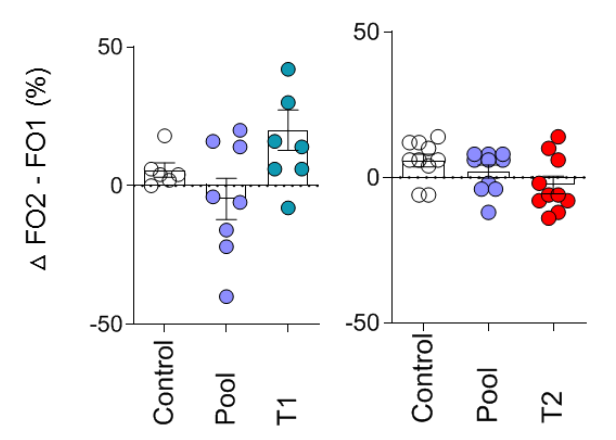

C

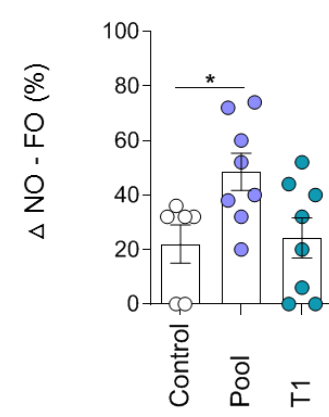

b

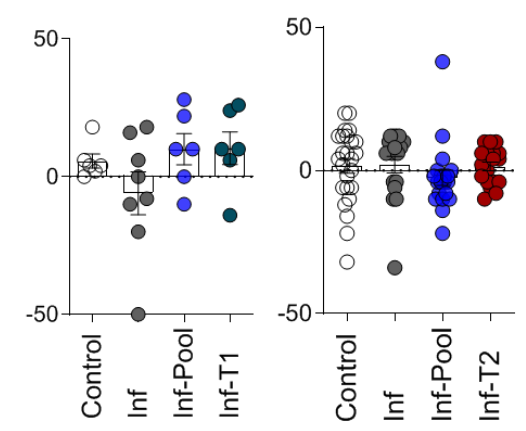

d

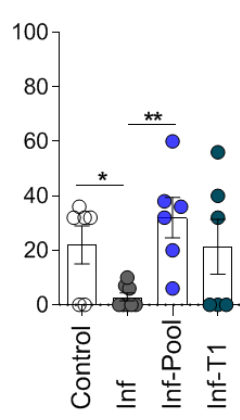

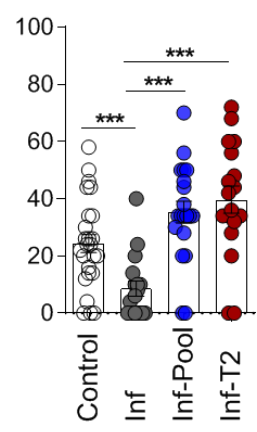

885

886

887

888

889

890

891

892

893

894

895

896

897

898

899

900

901

902

903

904

905

906

907

908

909
Fig. 2. Immune stimulation improves long-term memory performance in healthy and PbA-infected mice. Healthy or PbA-infected (and treated) mice were immune stimulated, or not, with the Pool, T1 or T2 strategies. Behavioural tasks were performed from day 88 to 92 post-infection ( 77 to 81 days after CQ treatment). During the training session of the New Object Recognition Task (NORT), all experimental groups explored the two objects, called familiar objects (FO1 and FO2, a, b) for the same length of time. In the test session, a new object (NO) is introduced in the task (c, d). Immune stimulation of healthy mice with Pool and T2 strategies (Pool and T2 groups) improved the exploratory time spent in the $\mathrm{NO}$ in relation to the Control group (c). PbA-infected mice (Inf group) presented similar exploration of NO and FO, showing a memory deficit, which was reversed after immune stimulation with Pool and T2 strategies (Pool and T2 groups) (d). Experimental groups: Control (non-infected / non-immune stimulated mice, $\mathrm{n}=6$ - 25); Pool (non-infected / Pool-immune stimulated mice, $\mathrm{n}=8$ - 10); T1 (noninfected / T1-immune stimulated mice, $\mathrm{n}=8$ ); T2 (non-infected / T2-immune stimulated mice, $n=10$ ); Inf (infected / non-immune stimulated mice, $n=6-17$ ); Inf-Pool (infected / Pool-immune stimulated mice, $n=6$ - 20); Inf-T1 (infected / T1-immune stimulated mice, $\mathrm{n}=6$ ); Inf-T2 (infected / T2-immune stimulated mice, $\mathrm{n}=8$ - 18). Data are expressed as mean and s.e.m. ${ }^{* *} \mathrm{P}<0.001$; ${ }^{* *} \mathrm{P}<0.01$; ${ }^{*} \mathrm{P}<0.05$; Mann-Whitney Unpaired t-test was used. Data shown represent one of two to five independent experiments (Control, Pool, T1, T2, Inf, Inf-Pool, Inf-T1); and a pool of two independent experiments (Control, Inf, Inf-Pool, Inf-T2). 
a

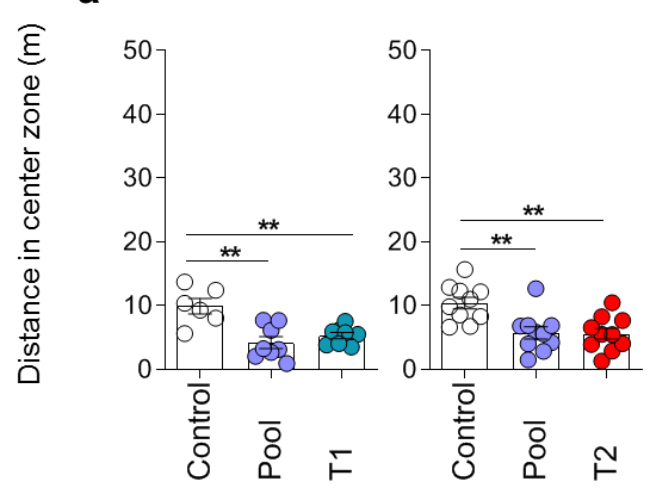

C

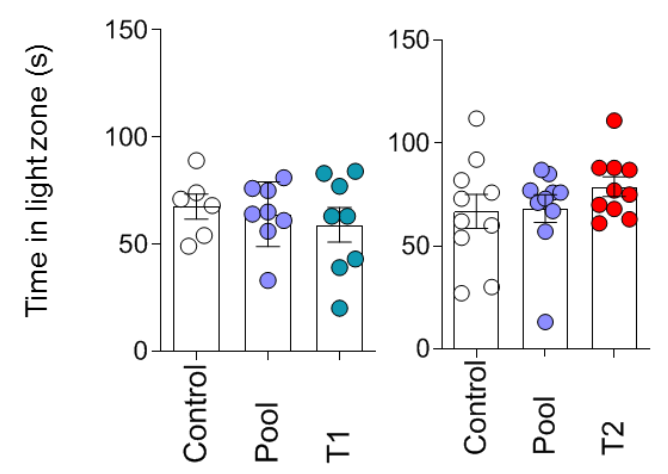

b

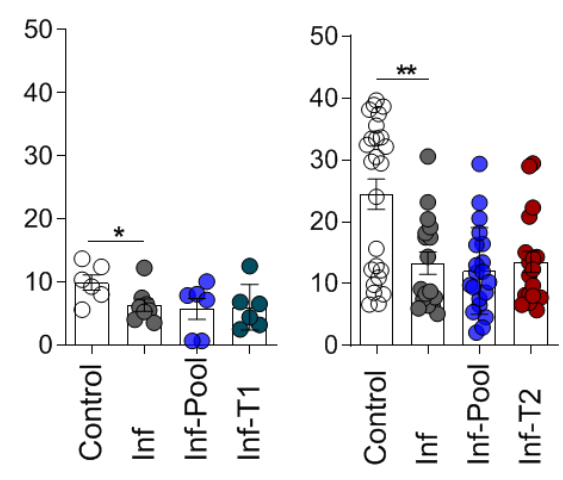

d

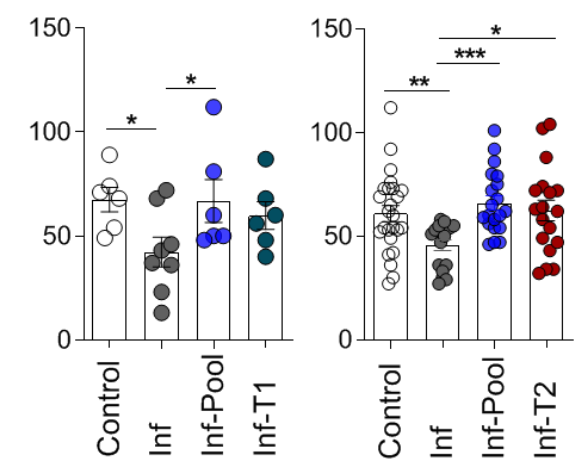

912

913

914

915

916

917

918

919

920

921

922

923

924

925

926

927

928

929

930

931

932

933
Fig. 3. Immune stimulation attenuates the anxiety-like behaviour observed in PbA-infected mice. Healthy or PbA-infected (and treated) mice were immune stimulated, or not, with the Pool, T1 or T2 strategies. Behavioural tasks were performed from day 88 to 92 post-infection ( 77 to 81 days after CQ treatment). During the training session of the Open Field Task (OFT), Pool, T1 and T2 immune stimulated groups (a) and $\mathrm{PbA}$-infected animals (Inf group) (b) showed a decrease in the distance travelled in the centre of the arena, as compared to the Control group. No difference was observed between the performance of Pool, T1, T2 and Control groups in the Light / Dark task (c). PbA-infected mice (Inf group) spent less time in the light zone of the Light / Dark apparatus. This anxiety-like behaviour was suppressed following immune stimulation with the Pool and T2 immune strategies (d). Experimental groups: Control (non-infected / non-immune stimulated mice, $\mathrm{n}=6-25)$; Pool (non-infected / Poolimmune stimulated mice, $\mathrm{n}=8$ - 10); T1 (non-infected / T1-immune stimulated mice, $\mathrm{n}$ = 8); T2 (non-infected / T2-immune stimulated mice, n = 10); Inf (infected / non-immune stimulated mice, $n=6$ - 17); Inf-Pool (infected / Pool-immune stimulated mice, $n=6$ 20); Inf-T1 (infected / T1-immune stimulated mice, $n=6$ ); Inf-T2 (infected / T2-immune stimulated mice, $n=8-18$ ). Data are expressed as mean and s.e.m. ${ }^{* * *} P<0.001 ;{ }^{* *} P$ $<0.01$; ${ }^{*} \mathrm{P}<0.05$; Mann-Whitney Unpaired t-test was used. Data shown represent one of two to five independent experiments (Control, Pool, T1, T2, Inf, Inf-Pool, Inf-T1); and a pool of two independent experiments (Control, Inf, Inf-Pool, Inf-T2). 
a

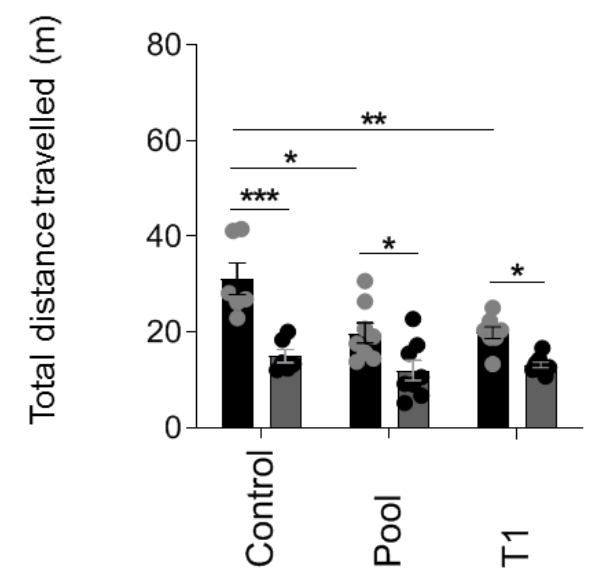

b

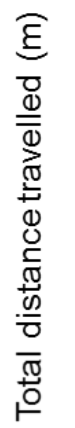

936

937

938

939

940

941

942

943

944

945

946

947

948

949

950

951

952
- OF1

- OF2

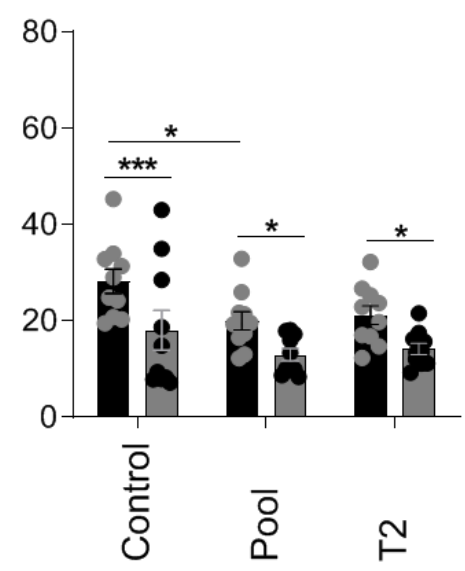

- OF1

- OF2

Extended data, Fig. 1. Immune stimulation and $P b A$ infection do not influence habituation memory in mice. Healthy or PbA-infected (and treated) mice were immune stimulated, or not, with the Pool, T1 or T2 strategies. Behavioural tasks were performed from day 88 to 92 post-infection ( 77 to 81 days after CQ treatment). Total distance travelled in the Open Field Task (OFT) during the training (OF1) and test session (OF2) in healthy and infected mice (a, b) were evaluated. OFT: healthy mice groups (Control, $n=6$; Pool, $n=8 ; T 1, n=8$ and Control, $n=10$; Pool, $n=10 ; T 2, n$ $=10$ ) and infected mice groups (Control, $n=6 ;$ Inf, $n=8$; Inf-Pool, $n=6 ;$ Inf-T1, $n=6$ and Control, $n=25 ;$ Inf, $n=17$; Inf-Pool, $n=20$; Inf-T2, $n=18)$. Data shown represent one of two to five independent experiments (Control, Pool, T1, T2, Inf, Inf-Pool, Inf-T1); and a pool of two independent experiments (Control, Inf, Inf-Pool, Inf-T2). 
a

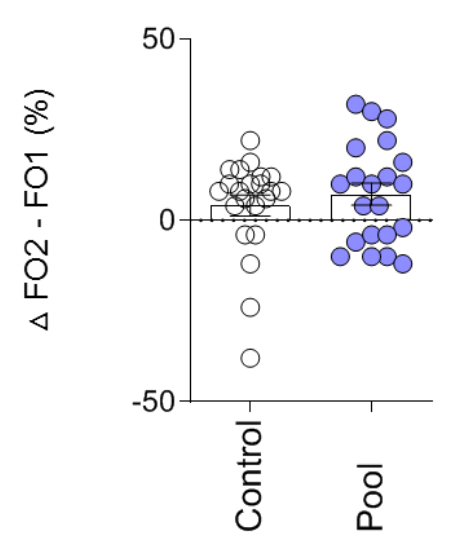

C

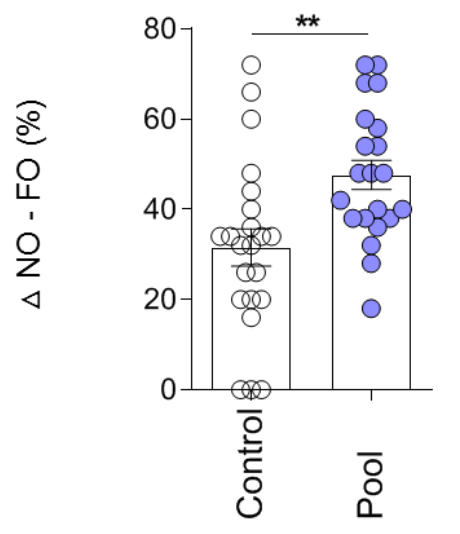

b

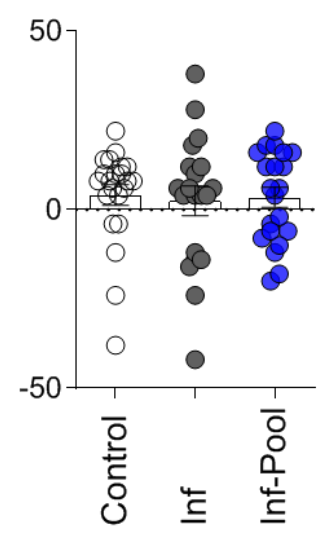

d

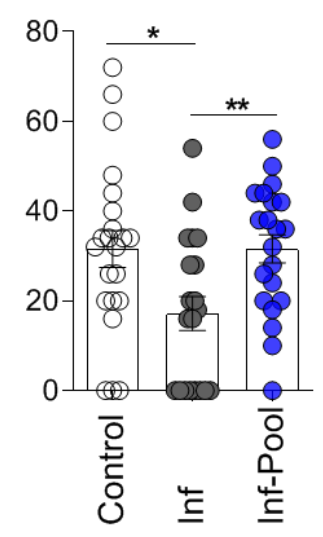

Extended data, Fig. 2. Immune stimulation improves long-term memory performance in healthy and $\mathbf{P b A}$-infected mice. Healthy or $\mathrm{PbA}$-infected (and treated) mice were immune stimulated, or not, with the Pool strategy. Behavioural tasks were performed from day 88 to 92 post-infection ( 77 to 81 days after CQ treatment). The exploration of the two familiar objects (FO1 and FO2), during the training session of NORT $(\mathbf{a}, \mathbf{b})$, and of the FO and the novel object (NO), during the test session (c, d), were explored and are expressed as differences in percentage of the exploration time. All groups of mice explored similarly the FO1 and FO2 during the training session (a, b). Immune stimulation of healthy mice with Pool strategy (Pool group) improved the exploratory time spent on the $\mathrm{NO}$ in relation to the $\mathrm{FO}$, as compared to the Control group (c). Pool-immune stimulation of $\mathrm{PbA}$-infected mice (Inf-Pool group) reversed the memory deficit of $P b A$-infected mice (Inf group) (d). NORT: healthy mice group (Control, $n=22$; Pool, $n=21$ ) and infected mice group (Control, $n=22$; Inf, $n=20$; InfPool, $n=21$ ). Data shown represent a pool of two independent experiments. Data are expressed as mean and s.e.m. ${ }^{* *} P<0.001$; ${ }^{* *} P<0.01$; ${ }^{*} P<0.05$; Two-way ANOVA $(a, b)$ and Unpaired t-test (c, d, e, f) was used. 


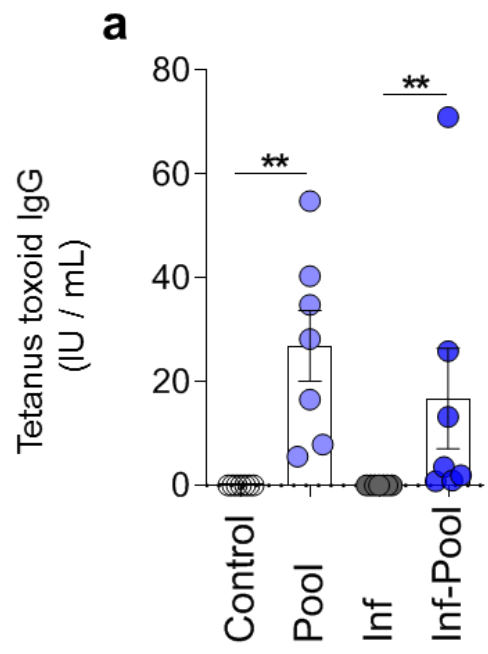

C

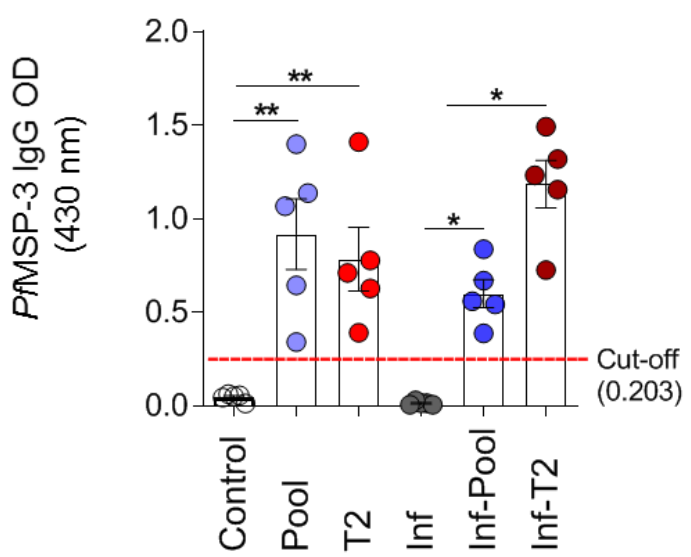

b

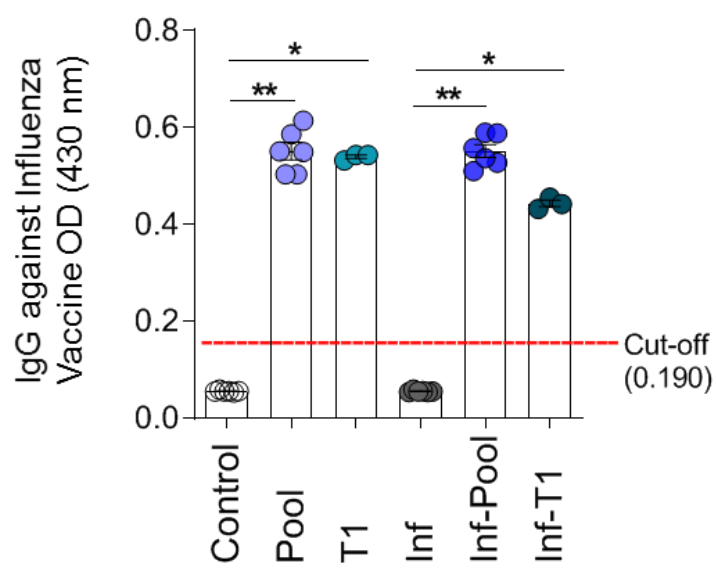

d

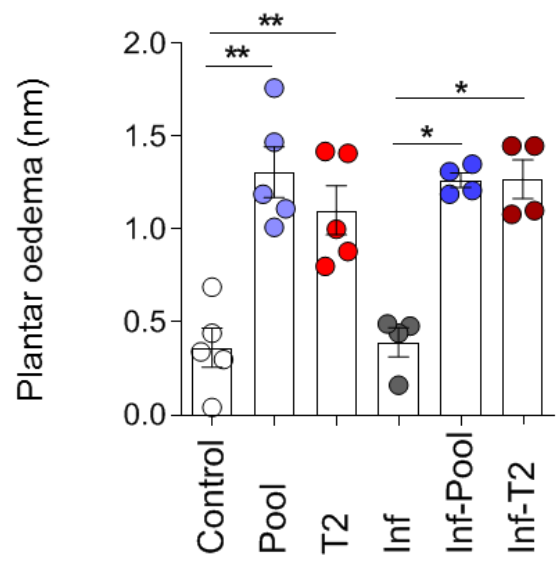

976

977

978

979

980

981

982

983

984

985

986

987

988

989

990

991

992

993

Extended data, Fig. 3. Immune stimulation with $\mathrm{dT}$ and influenza vaccines, PfMSP-3 and OVA proteins triggers specific immune responses. Healthy or PbAinfected (and treated) mice were immune stimulated, or not, with the strategies: Pool, T1 or T2. After behavioural evaluation, mice were randomly chosen for the analysis of the effectiveness of immune stimulation. Serum levels of (a) dT-specific $\lg G(n=7)$, (b) Influenza-specific IgG ( $n=3-6)$, and (c) PfMSP-3-specific IgG $(n=5)$ were measured. e, Reaction to OVA was elicited by intradermal injection of the antigen in the footpad of the OVA-sensitized mice. Oedema was determined by measuring the thickness of the paw before and after inoculation $(n=4-5)$. Experimental groups: Control (non-infected / non-immune stimulated); Pool (non-infected / Pool-immune stimulated); T1 (non-infected / T1-immune stimulated); T2 (non-infected / T2-immune stimulated); Inf (infected / non-immune stimulated); Inf-Pool (infected / Pool-immune stimulated); Inf-T1 (infected / T1-immune stimulated); Inf-T2 (infected / T2-immune stimulated). Data are expressed as mean and s.e.m. ${ }^{\star *} P<0.01$; ${ }^{*} P<0.05$; Unpaired t-test with Mann-Whitney test was used. 

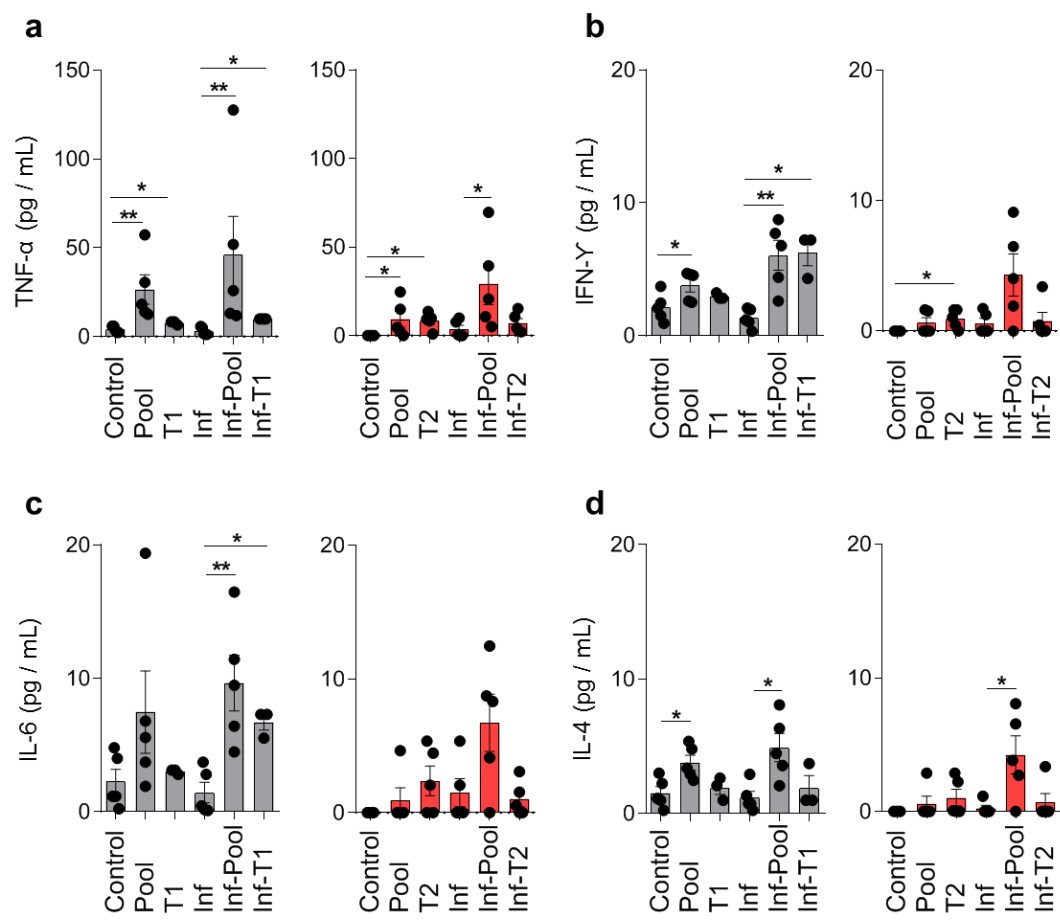

d
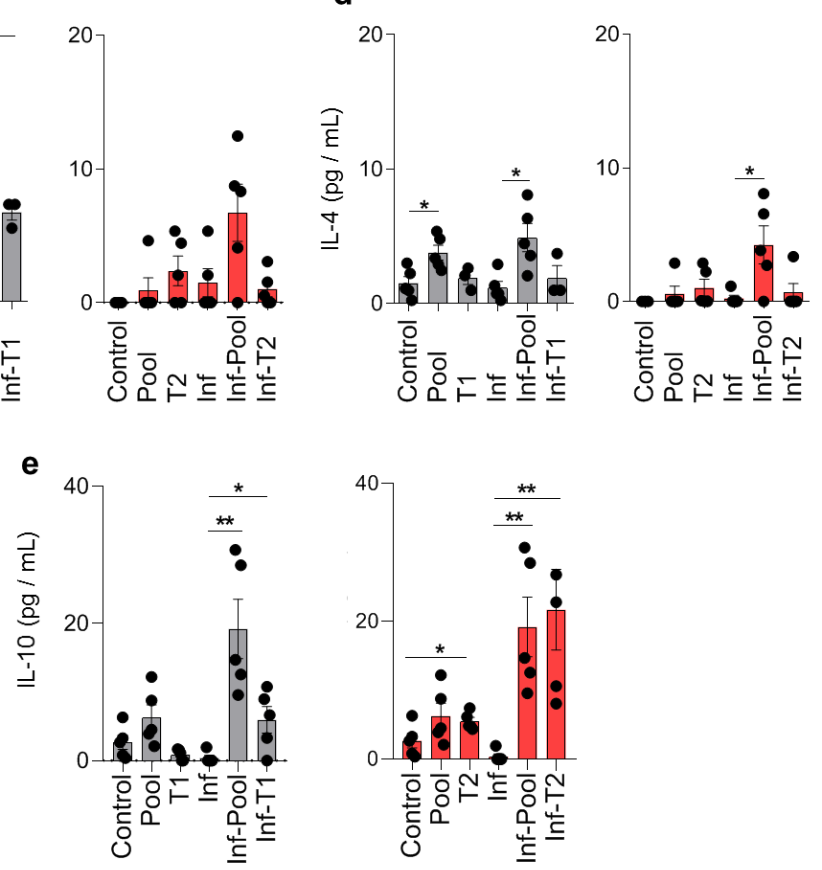

997

998

Extended data, Fig. 4. Immune stimulation with the different strategies elicits cellular responses measured by increased serum cytokine levels. Healthy or infected (and treated) mice were immune stimulated, or not, with the strategies: Pool, T1 or T2. Serum samples were collected after the behavioural evaluation (84 days after the end of CQ treatment), and levels of the cytokines (a) TNFa, (b) IFN IL-4 and (e) IL-10 were quantified by flow cytometry using cytometric bead array. Experimental groups: Control (non-infected / non-immune stimulated, $n=3-5$ ); Pool (non-infected / Pool-immune stimulated, $\mathrm{n}=5$ ); T1 (non-infected / T1-immune stimulated, $n=3$ ); T2 (non-infected / T2-immune stimulated, $n=5$ ); Inf (infected / nonimmune stimulated, $n=5$ ); Inf-Pool (infected / Pool-immune stimulated, $n=5$ ); Inf-T1 (infected / T1-immune stimulated, $\mathrm{n}=3$ ); Inf-T2 (infected / T2-immune stimulated, $\mathrm{n}=$ 5). Data are representative of three (Control, Pool, Inf and Inf-Pool groups) and one (T1, T2, Inf-T1 and Inf-T2 groups) independent experiments. Data are expressed as mean and s.e.m. ${ }^{* *} P<0.01 ;{ }^{*} P<0.05$; Unpaired t-test with Mann-Whitney test was used. 
a

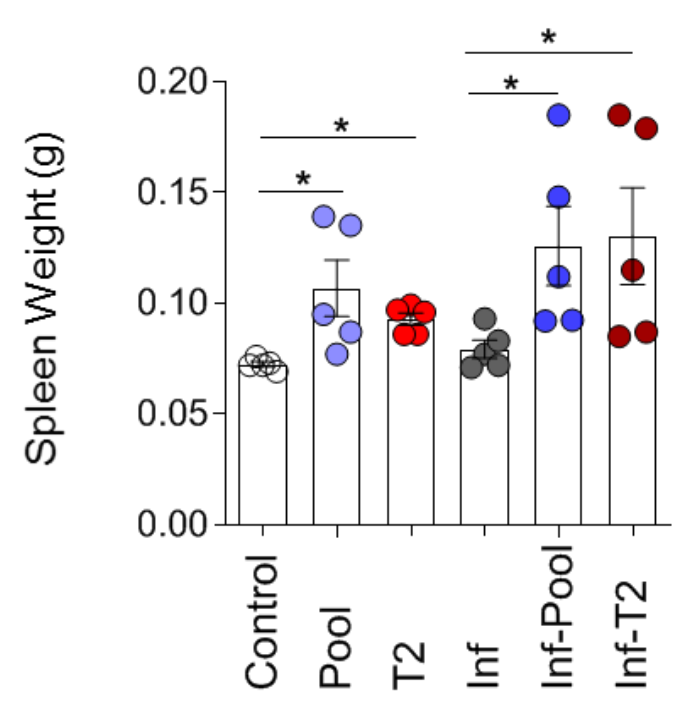

b

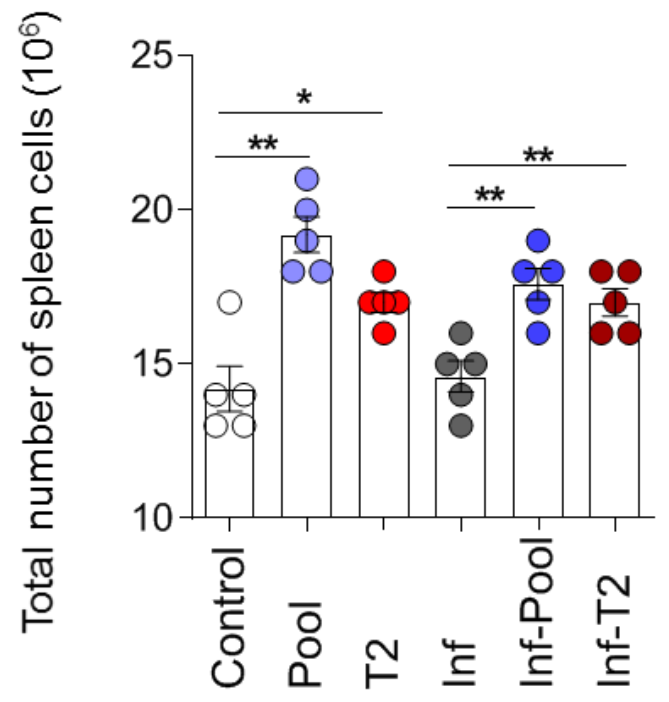

1016

1017

1018

1019

1020

1021

1022

1023

1024

1025

1026

1027

1028

1029

1030

1031

C

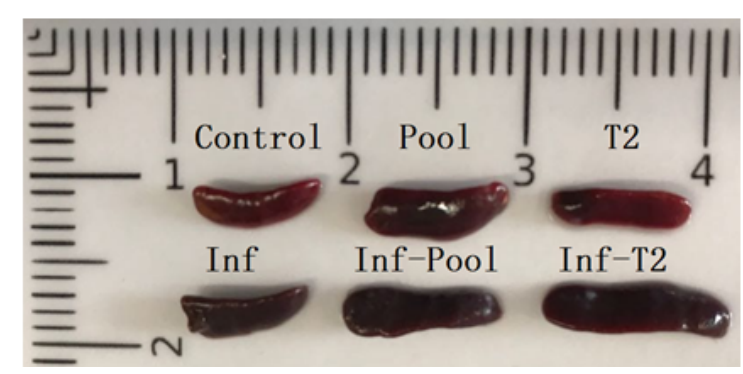

Extended data, Fig. 5. Splenic enlargement is observed after immune stimulation. Healthy or infected (and treated) mice were immune stimulated, or not, with the Pool or T2 strategy. Spleen weight (a) and total number of splenocytes (b) were evaluated at the end of the cognitive behavioural tasks $(n=5)$ ( 84 days after the end of CQ treatment). c, Representative photograph of Control, Pool, T2, Inf, Inf-Pool and Inf-T2 groups. Groups of infected mice showed a dark colour attributed to hemozoin, even more than two and a half months after infection. Experimental groups: Control (non-infected / non-immune stimulated); Pool (non-infected / Pool-immune stimulated); T2 (non-infected / T2-immune stimulated); Inf (infected / non-immune stimulated); Inf-Pool (infected / Pool-immune stimulated); Inf-T2 (infected / T2-immune stimulated). Data are mean and s.e.m. ${ }^{* *} P<0.01$; ${ }^{*} P<0.05$; Unpaired t-test with Mann-Whitney test was used. 
Extended data, Fig. 6. Stimulation of the immune system by the Pool and T2 or T2 strategy. Splenic lymphocytes subpopulations were analysed at the end of the cognitive behavioural tasks (84 days after the end of $C Q$ treatment), when five mice were randomly chosen per group. a, Representative gating strategy to identify the populations of $\mathrm{B}$ cells $\left(\mathrm{B220^{+ }}\right)$, CD4 T cells $\left(\mathrm{CD} 3^{+} \mathrm{CD} 4^{+}\right)$, CD8 T cells $\left(\mathrm{CD} 3^{+} \mathrm{CD} 8^{+}\right)$and Treg cells $\left(\mathrm{CD}^{+}{ }^{+} \mathrm{CD} 4^{+} \mathrm{CD} 25^{+}\right.$Foxp3 $\left.{ }^{+}\right)$by flow cytometry. Percentage of $\mathrm{B}$ cells (b), CD4 T cells (c) and CD8 T cells (d) per spleen. e, Percentage of Treg cells among the CD4 $\mathrm{T}$ cells population. Experimental groups: Control (non-infected / non-immune stimulated); Pool (non-infected / Pool-immune stimulated); T2 (non-infected / T2immune stimulated); Inf (infected / non-immune stimulated); Inf-Pool (infected / Poolimmune stimulated); Inf-T2 (infected / T2-immune stimulated). Data are expressed as mean and s.e.m. ${ }^{* *} P<0.01 ;{ }^{*} P<0.05$; Unpaired t-test with Mann-Whitney test was used. 

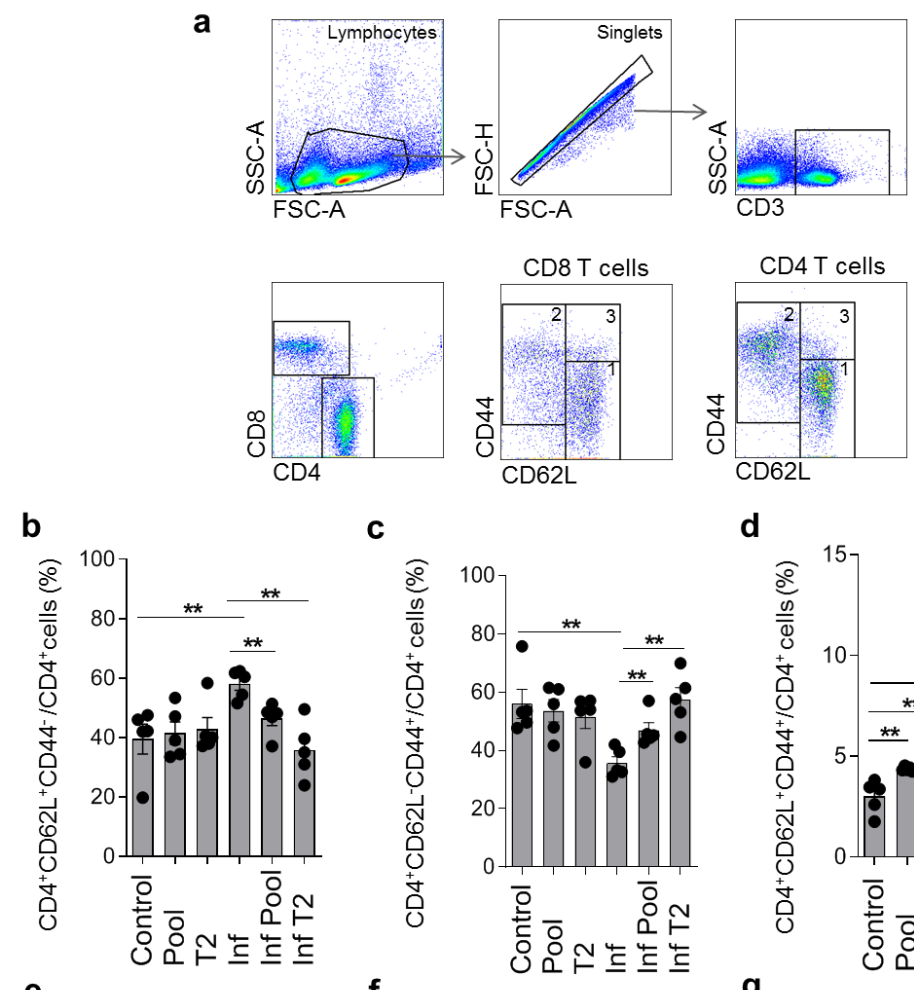

C
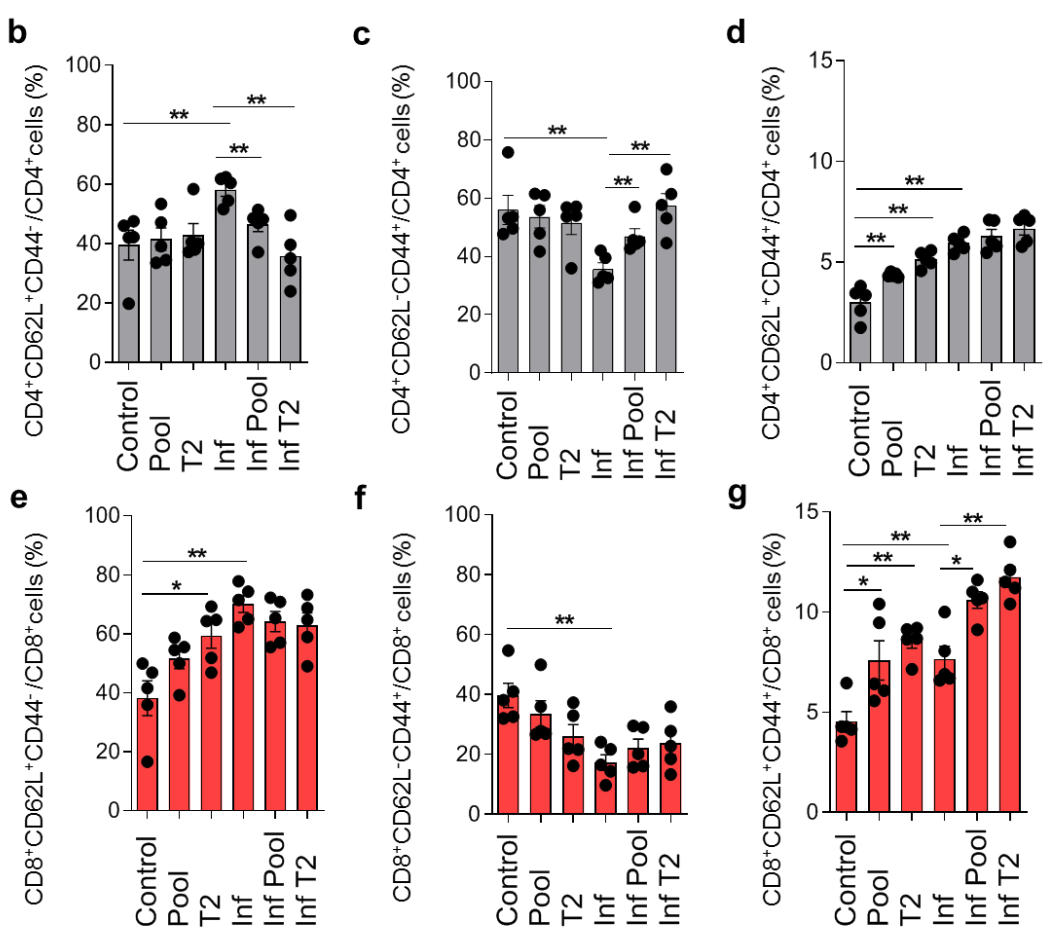

Extended data, Fig. 7. Effect of immune stimulation with the Pool and T2 strategies on the activation and memory phenotypes of CD4 and CD8 T cells. Healthy or infected (and treated) mice were immune stimulated, or not, with Pool or T2 strategy. Splenic lymphocyte subpopulations were analysed at the end of the cognitive behavioural tasks (84 days after the end of $C Q$ treatment), when five mice were randomly chosen per group. a, Representative gating strategy to identify the subpopulations of naïve (gate: 1 ; CD44 ${ }^{-} \mathrm{CD} 62 \mathrm{~L}^{+}$); effector / effector memory (gate: 2; CD44 ${ }^{+} \mathrm{CD} 62 \mathrm{~L}^{-}$) and central memory (gate: 3 ; $\mathrm{CD}_{4} 4^{+} \mathrm{CD} 2 \mathrm{~L}^{+}$) $\mathrm{CD} 4$ and CD8 T cells by flow cytometry. Percentage of naïve, effector / effector memory and central memory CD4 T cells (b-d) and CD8 T cells (e-g). Experimental groups: Control (non-infected / non-immune stimulated); Pool (non-infected / Pool-immune stimulated); T2 (noninfected / T2-immune stimulated); Inf (infected / non-immune stimulated); Inf-Pool (infected / Pool-immune stimulated); Inf-T2 (infected / T2-immune stimulated). Data are mean and s.e.m. ${ }^{* *} P<0.01$; ${ }^{*} P<0.05$; Unpaired t-test with Mann-Whitney test was used. 

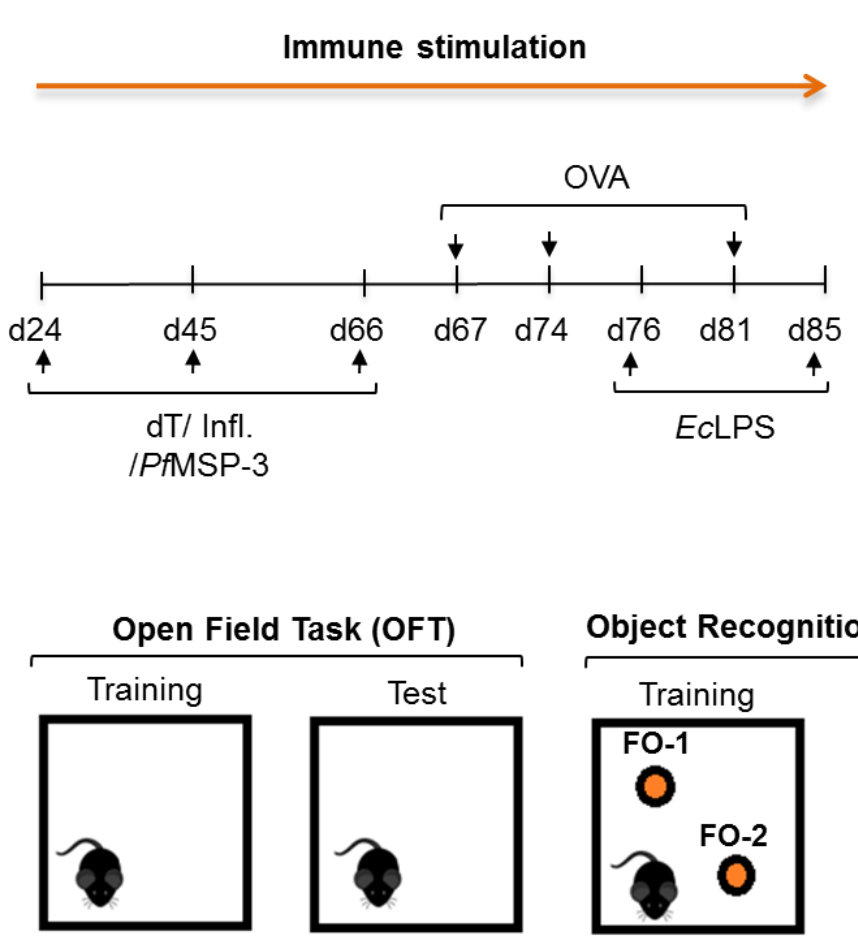

d1

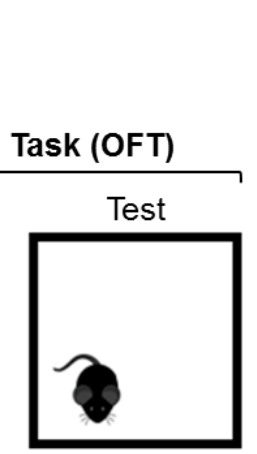

d2

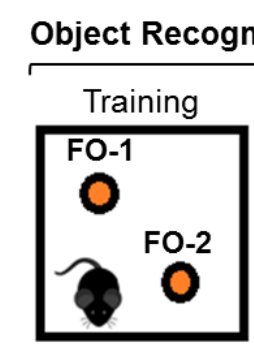

d3

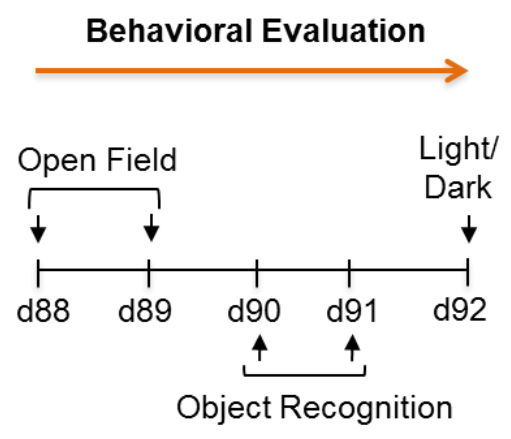

$\downarrow$
1074

1075

1076

1077

1078

1079

1080

1081

1082

1083

1084

1085

1086

1087

1088

1089

1090

1091

1092

1093

1094

1095

1096

1097
Fig. 1 Material \& Methods. Flow chart of immune stimuli and behavioural assessment. Mice (infected or not with $P b A$ and treated with $C Q$ ) were immune stimulated or non-immune stimulated, according to the composition of the immunization (Pool, T1 and T2) strategies used. Three doses of the dT and Influenza vaccines and the PfMSP-3 recombinant protein were inoculated conjointly, in different pathways, with a twenty-day interval between inoculations. Three doses of OVA, with a six-day interval between each one, were inoculated one day after the third dose of dT and Influenza vaccines and PfMSP-3 protein. The first injection of ECLPS was done two days after the second dose of OVA, being the second of two injections administered nine days after the first one. Assessment of performance on behavioural tasks started 88 to 92 days post infection (77 to 81 days after the complete parasitological cure of animals obtained with $\mathrm{CQ}$ treatment). The beginning of behavioural tests corresponded to 22 days after the last stimulation with the vaccines (Tetanus-Diphtheria and Influenza) and the PfMSP-3 recombinant protein; 7 days after the latter injection of Ovalbumin; and 3 days after the LPS final inoculation. The open field was performed to measure locomotivity, spatial habituation memory and anxiety phenotype, in two sessions [training (OF1) and test (OF2)]. Thereafter, the new object recognition task (NORT) was performed to measure long-term recognition memory, also in two sessions at consecutive days (training and testing). Finally, the anxious behaviour phenotype was specifically evaluated, by the light-dark test, in a unique session. 
1098 Table 1. Immune stimulus inoculation strategy: route, region, concentration, volume 1099 and number of injections of immunogens.

1100

\begin{tabular}{cccccc}
\hline Immune Stimuli & Route & Region & Concentration & Volume Inoculation \\
\hline dT vaccine & Subcutaneous & Back & $\begin{array}{c}1 / 5 \text { human } \\
\text { dose }\end{array}$ & $100 \mu \mathrm{l}$ & 3
\end{tabular}

\begin{tabular}{|cllccc|}
\hline Influenza vaccine & Intramuscular & Quadriceps & $\begin{array}{c}1 / 5 \text { human } \\
\text { dose }\end{array}$ & $100 \mu \mathrm{l}$ & 3 \\
\hline pfMSP-3 & Subcutaneous & Base Tail & $10 \mu \mathrm{g}$ & $100 \mu \mathrm{l}$ & 3 \\
\hline
\end{tabular}

ecLPS Intraperitoneal Abdomen $0,1 \mathrm{mg} / \mathrm{kg} \quad 100 \mu \mathrm{l}$

\begin{tabular}{|c|c|c|c|c|}
\hline Ovalbumin & $\begin{array}{l}\text { Subcutaneous } \\
\text { Intraperitoneal }\end{array}$ & $\begin{array}{l}\text { Back and } \\
\text { Abdomen }\end{array}$ & $50 \mu \mathrm{g}$ & $200 \mu \mathrm{l}$ \\
\hline
\end{tabular}

1103 i.p.: intraperitoneal 